Article

\title{
Flow Behavior and Displacement Mechanisms of Nanoparticle Stabilized Foam Flooding for Enhanced Heavy Oil Recovery
}

\author{
Teng Lu*, Zhaomin $\mathrm{Li}^{*}$ and Yan Zhou \\ College of Petroleum Engineering, China University of Petroleum, Qingdao 266580, China; \\ s16020308@s.upc.edu.cn \\ * Correspondence: luteng@upc.edu.cn (T.L.); lizhm@upc.edu.cn (Z.L.); \\ Tel.: +86-532-8698-1717 (T.L.); +86-532-8698-1283 (Z.L.) \\ Academic Editor: Dongsheng Wen \\ Received: 2 December 2016; Accepted: 6 April 2017; Published: 20 April 2017
}

\begin{abstract}
In this study, nanoparticle stabilized foam experiments were performed in bulk tests, micromodels, and sandpacks at elevated temperatures and pressures to investigate the flow behavior and displacement mechanisms for enhanced heavy oil recovery. The results from the bulk tests showed that the stability of the foam and oil in water $(\mathrm{O} / \mathrm{W})$ emulsion improved when silica nanoparticles $\left(\mathrm{SiO}_{2}\right)$ were added, compared with the anionic surfactant alone. Also, the $\mathrm{SiO}_{2}$ nanoparticles increased the dilatational viscoelasticity of the gas-water interface, which is an important fluid property and mechanism for improving heavy oil recovery. The micromodel studies demonstrated that several gas bubbles and oil droplets were stably dispersed during the nanoparticle stabilized foam flooding. The gas bubbles and oil droplets plug pores through capture-plugging and bridge-plugging, thereby increasing the sweep efficiency. The trapped residual oil is gradually pushed to the pores by the elastic forces of bubbles. Subsequently, the residual oil is pulled into oil threads by the flowing gas bubbles. Then, a greater improvement in displacement efficiency is obtained. The sandpack tests showed that the tertiary oil recovery of nanoparticle stabilized foam flooding can reach about $27 \%$ using $0.5 \mathrm{wt} \% \mathrm{SiO}_{2}$ nanoparticles. The foam slug size of 0.3 pore volume (PV) and the gas liquid ratio (GLR) of 3:1 were found to be the optimum conditions in terms of heavy oil recovery by nanoparticle stabilized foam flooding in this study. A continuous nanoparticle dispersion and $\mathrm{N}_{2}$ could be more effective compared with the cyclic injection pattern.
\end{abstract}

Keywords: nanoparticle stabilized foam flooding; enhanced oil recovery; heavy oil; flow behavior; micromodel test

\section{Introduction}

Due to increasing petroleum demand, the exploitation of heavy oil reserves has increased significantly in recent years. The global heavy oil reserves are abundant and are estimated to be around $6.04 \times 10^{11} \mathrm{~m}^{3}-9.86 \times 10^{11} \mathrm{~m}^{3}$ in total. However, due to high oil viscosity, the performance of the primary recovery is bad in heavy oil reservoirs [1-3].

For the heavy oil reservoirs with oil viscosities lower than $10,000 \mathrm{mPa} \cdot \mathrm{s}$, water flooding can be conducted as a secondary oil recovery method. However, because of the poor mobility ratio between heavy oil and water, water flooding does not have a satisfactory performance $[4,5]$. Due to this reason, even after water flooding, a significant amount of oil still remains in the reservoir. To recover the remaining oil after water flooding in heavy oil reservoirs, enhanced oil recovery (EOR) methods can be applied such as thermal recovery methods, surfactant flooding, polymer flooding, and foam flooding [6-9]. 
Because the viscosity of heavy oil is much higher than that of gas, the recovery performance of gas flooding is quite low. Previous studies have demonstrated that foam flooding can reduce the gas mobility and increase the sweep efficiency, thereby improving the heavy oil recovery [10-12]. The stability of foam is very important for the foam flooding [13,14]. Nanoparticles, such as silica, can improve the stability and recovery performance of foam flooding. Sun et al. [15] investigated the stability and the effect of foam stabilized with silica nanoparticles and Sodium Dodecyle Sulfate (SDS) on enhanced light oil recovery. Nguyen et al. [16] studied the flow behaviors of nanoparticle-stabilized $\mathrm{CO}_{2}$ foam in improving light oil recovery at the pore and micromodel scales. The authors of the study found that the effectiveness of nanoparticle-stabilized $\mathrm{CO}_{2}$ foam is comparable for representative light, medium, and heavy oils. All three oils showed substantial additional oil recovery and a potentially valuable reservoir homogenization effect. Singh and Mohanty [17] studied foam stabilization by in-situ surface activation of hydrophilic nanoparticles for subsurface applications. The corefloods in the sandstone cores in a light oil reservoir showed that immiscible foams with a surface-modified nanoparticle (SMNP) solution can recover significantly more oil than water flooding. By using computed tomography (X-ray CT) scanning techniques, Aminzadeh et al. [18] found that compared to the foam flooding without nanoparticles, the $\mathrm{SiO}_{2}$ stabilized $\mathrm{N}_{2}$ foam can improve sweep efficiency and reduce the gravity override.

While nanoparticle-stabilized foam flooding has extensively been investigated in light oil reservoirs, limited data are available for nanoparticle-stabilized foam flooding in improving the recovery of heavy oil. For the heavy oil reservoir, the mobility of heavy oil is much lower than water and gas. Improving the stability of foam is very important for the application of foam flooding in the heavy oil reservoir. Therefore, the flow behaviors of nanoparticle-stabilized foam flooding in heavy oil reservoirs are more complicated than that in light oil reservoirs. This paper provides the microscopic displacement mechanisms and recovery performance of nanoparticle-stabilized foam flooding for enhancing heavy oil recovery.

\section{Experimental}

\subsection{Materials}

The oil sample was collected from the Shengli Oilfield in China. The viscosity, density, saturates, aromates, resins, and asphaltenes (SARA) analyses results, and the acid number of the heavy oil are listed in Table 1.

Table 1. Properties of the heavy oil sample.

\begin{tabular}{|c|c|c|c|c|c|c|}
\hline $\begin{array}{c}\text { Density at } \\
60^{\circ} \mathrm{C}\left(\mathrm{kg} / \mathrm{m}^{3}\right)\end{array}$ & $\begin{array}{c}\text { Viscosity at } \\
60{ }^{\circ} \mathrm{C}(\mathrm{mPa} \cdot \mathrm{s})\end{array}$ & $\begin{array}{c}\text { Saturate } \\
\text { (wt \%) }\end{array}$ & $\begin{array}{c}\text { Aromatic } \\
(w t \%)\end{array}$ & $\begin{array}{l}\text { Resin } \\
\text { (wt \%) }\end{array}$ & $\begin{array}{c}\text { Asphaltenes } \\
\text { (wt \%) }\end{array}$ & $\begin{array}{c}\text { Acid Number } \\
\text { (mg KOH/g oil) }\end{array}$ \\
\hline 986.8 & 2240 & 39.19 & 38.49 & 19.58 & 2.35 & 2.71 \\
\hline
\end{tabular}

$\mathrm{N}_{2}$ gas used was provided by Tianyuan Co., Ltd., Qingdao, China and had a purity of $99.99 \%$. A commercial surfactant Hengye-2 (HY-2) (anionic, provided by Shengli Oilfield, Dongying, China, with a purity of $33.5 \%$ ) was used as the foaming agent. The brine was prepared by a $\mathrm{NaCl}$ solution with a salinity of $7500 \mathrm{mg} / \mathrm{L}$. The partially hydrophobic $\mathrm{SiO}_{2}$ nanoparticles (HDK, H15) were supplied by Wacker Chemie AG, Burghausen, Germany. The average diameter and surface area of the hydrophobic $\mathrm{SiO}_{2}$ nanoparticles were about $14 \mathrm{~nm}$ and $200 \mathrm{~m}^{2} / \mathrm{g}$, respectively. Distilled water was used to make all the necessary solutions.

\subsection{Nanoparticle-Surfactant Dispersion}

A nanoparticle-surfactant dispersion was prepared by mixing $1.0 \mathrm{wt} \%$ nanoparticles and $0.5 \mathrm{wt} \%$ HY-2 surfactant. The mixture was stirred for $24 \mathrm{~h}$ and was then ultrasonicated for $1 \mathrm{~h}$. 


\subsection{Preparation and Characterization of Foam}

The foam was generated according to the Waring Blender method in a thermostat under different temperatures [19]. Using a blender, a $100 \mathrm{~mL}$ dispersion was stirred for $3 \mathrm{~min}$ at $7000 \mathrm{rpm}$ to generate the foam. The foam was poured into a cylinder. The time taken to drain $50 \mathrm{~mL}$ liquid from the foam (half-life) was recorded.

The surface dilational viscoelasticity of the dispersion was measured by using a bubble/drop profile analysis tensiometer (Tracker-H, Teclis Instruments, Longessaigne, France). The principle of surface dilational viscoelasticity has been described in one of our previous studies [19]. The same setup was used to determine the surface rheological properties. After $3000 \mathrm{~s}$ of bubble formation, oscillations were performed with bubble area sinusoidal oscillations of relative amplitude $\delta S / S_{0}=15 \%$. The dilatational modulus versus the oscillation frequency ranged from 0.05 to $0.2 \mathrm{~Hz}$. The temperature of the measuring cell was kept constant at $30^{\circ} \mathrm{C}$.

\subsection{Emulsification Tests}

Two kinds of emulsification tests were conducted in the present study. The first one was the bottle test, which was conducted in $50 \mathrm{~mL}$ bottles. Two bottles were used, which contained brine and the nanoparticle-surfactant dispersion. First, $40 \mathrm{~mL}$ of aqueous phase (brine or nanoparticle-surfactant dispersion) was placed in a test bottle. Then, using a syringe, $10 \mathrm{~mL}$ of oil was poured into the top of the brine or nanoparticle-surfactant dispersion slowly. The bottles were turned upside down to mix the oil and aqueous phase.

The second emulsification test was conducted to investigate the effect of nanoparticles on the emulsion stability. For these tests, $100 \mathrm{~mL}$ of aqueous phase $(0.5 \mathrm{wt} \% \mathrm{HY}-2$ solution or nanoparticle-surfactant dispersion) was placed in the blender. Then, $20 \mathrm{~mL}$ of oil was added to the aqueous phase in the blender. To form the oil in water $(\mathrm{O} / \mathrm{W})$ emulsion, the aqueous phase with oil was stirred for $3 \mathrm{~min}$ at $500 \mathrm{rpm}$. Then the emulsion was poured into a sealed cylinder. The time taken to drain $50 \mathrm{~mL}$ of the aqueous phase from the emulsion (half-life) was recorded. The emulsification tests were conducted at room temperature.

\subsection{Micromodel Setup}

The micromodel test experimental setup is shown in Figure 1. An ISCO pump (model 100 DX) delivered crude oil, brine, and the nanoparticle-surfactant dispersion to the micromodel at a preset and constant flow rate. A diaphragm back pressure regulator (BPR) with a pressure accuracy of $0.001 \mathrm{MPa}$ was used to control the back pressure. The high-pressure visual cell allowed an overburden pressure of up to $10.0 \mathrm{MPa}$, and a temperature up to $180^{\circ} \mathrm{C}$. The confinement fluid in the visual cell was water. The visual cell had two transparent windows: the upper one for viewing the micromodel, and the lower one for illuminating it. A heating muff outside of the visual cell was used to heat the cell to a certain high temperature. As shown in Figure 2, a quarter 5-spot glass-etched micromodel was placed in the high-pressure visual cell horizontally. The micromodel was made of two high pressure-resisting glasses. The lower plate had two holes for injecting and retrieving the fluids. The micromodel was constructed by etching a two-dimensional network of pores and throats using a photochemical method. The pore network used in this study was patterned based on the pore structure of a core obtained from the reservoir. The size of the network was $5 \mathrm{~cm} \times 5 \mathrm{~cm}$, and the depth and width of the microscopic channel were approximately $40 \mu \mathrm{m}$ each. The porosity and permeability of the micromodel were about 0.45 and $2.5 \mu \mathrm{m}^{2}$, respectively. A Nikon Model L110 digital camera was used to record images within the micromodel. As shown in Figure 1b, a foam generator, which was a porous medium sealed in the flow channel, was used upstream of the micromodel. The foam generator was filled with the silica sand, with diameters of about $70 \mu \mathrm{m}-100 \mu \mathrm{m}$. Then the foam was generated by passing the gas and surfactant-containing liquid simultaneously through the foam generator. 

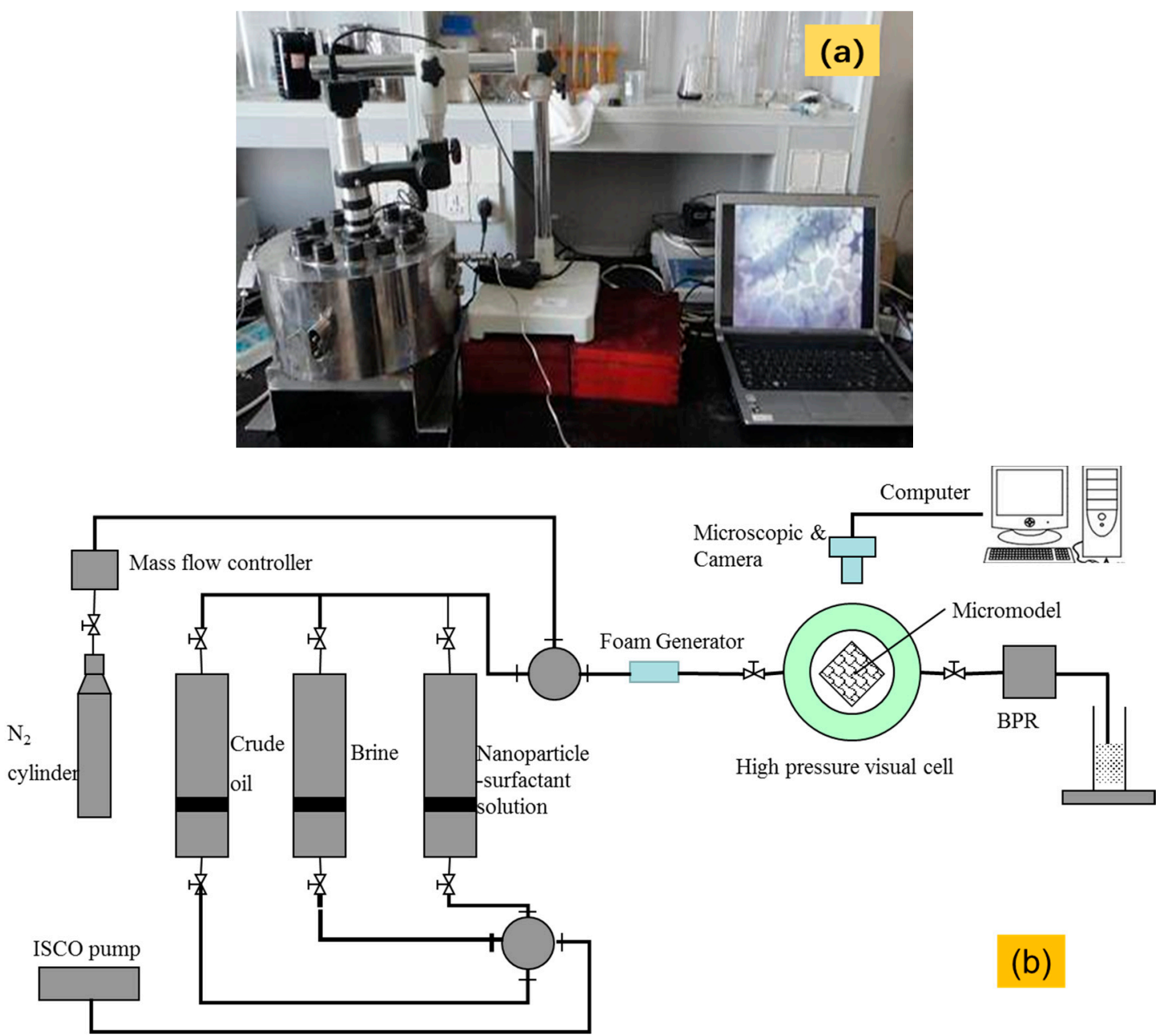

Figure 1. (a) Image of the micromodel test experimental setup; (b) a simplified schematic of the micromodel test experimental setup.

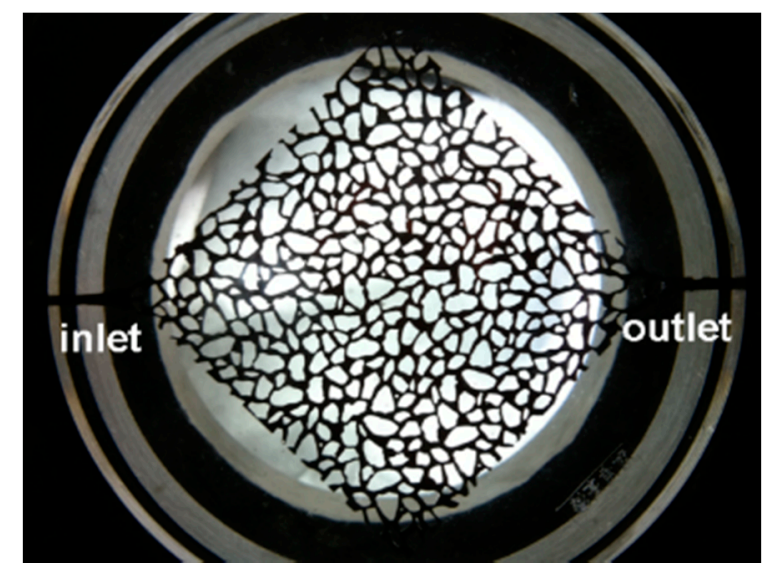

Figure 2. Image of the micromodel.

After the micromodel was vacuumed, it was saturated by the oil. The back pressure during the micromodel test was set to be $2.0 \mathrm{MPa}$. Then, the brine was introduced into the micromodel at $0.004 \mathrm{~mL} / \mathrm{min}$. After 1.0 pore volume (PV) of brine was injected, nanoparticle-stabilized foam flooding was conducted. The nanoparticle-surfactant dispersion and $\mathrm{N}_{2}$ were injected simultaneously. 
The injection rate of the nanoparticle-surfactant dispersion and $\mathrm{N}_{2}$ were both set to be $0.002 \mathrm{~mL} / \mathrm{min}$. Therefore, the gas liquid ratio (GLR) was 1:1 during the micromodel test. To distinguish the water phase from the gas phase, $0.05 \mathrm{wt} \%$ eosin- $Y$ was added to the nanoparticle-surfactant dispersion [2]. The experiment was conducted at $60{ }^{\circ} \mathrm{C}$.

\subsection{Sandpack Flood Studies}

The sanpack test experimental setup is shown in Figure 3. All the sandpacks had a diameter and length of 2.54 and $60.00 \mathrm{~cm}$, respectively. Firstly, the sandpack was packed as follows: a coreholder filled with brine was positioned vertically, and fresh quartz sands with size fractions of 80-100 meshes were added in several increments to fill the coreholder. In each step, the sand was shaken slightly after being poured in. During this process, the water surface was kept above the top of the sand to ensure that air was not introduced into the sample. The sandpack tests were conducted horizontally. The brine was injected into the sandpack to obtain the porosity and permeability. The sandpack was flooded with the crude oil to establish the initial oil saturation with the injection rate of $0.05 \mathrm{~mL} / \mathrm{min}$ at $60{ }^{\circ} \mathrm{C}$. The water flooding was conducted in the sandpack until the water cut was up to $98 \%$. To study the recovery performance of foam flooding, $\mathrm{N}_{2}$ and chemical slugs were injected. The foam flooding was followed by a subsequent water flooding until the water cut was up to $98 \%$. The back pressure and temperature of the sandpack tests were set to be $3.0 \mathrm{MPa}$ and $60^{\circ} \mathrm{C}$, respectively.

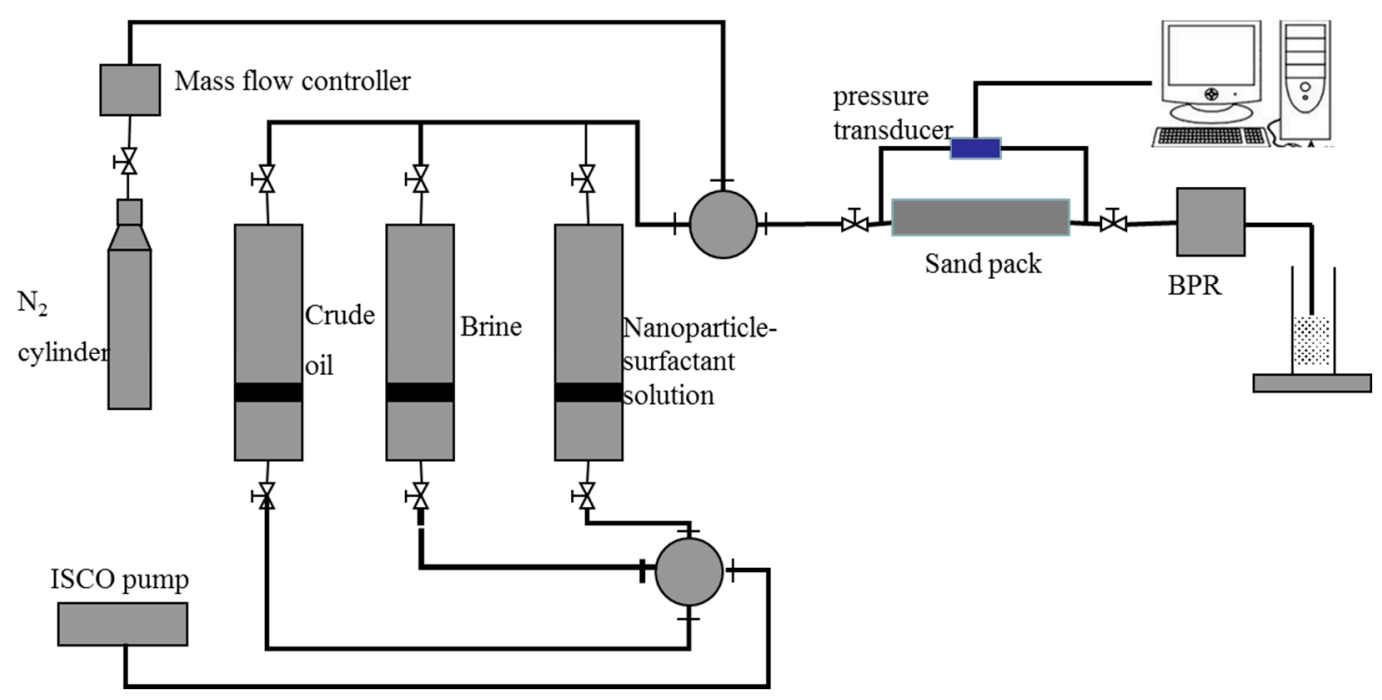

Figure 3. Simplified schematic of the sandpack test experimental setup.

\section{Results and Discussion}

\subsection{Characterization of the Foam in Bulk Tests}

Figure 4 shows the half-life of different foam systems at different temperatures. It is observed that the half time of the $\mathrm{SiO}_{2} / \mathrm{HY}-2$ foam system was much higher than that of the HY-2 foam system at different temperatures, indicating that $\mathrm{SiO}_{2}$ nanoparticles can improve the stability of the foam. Figure 5 shows the dilational viscoelasticity of the different systems. The dilational viscoelasticity is an important property for gas bubbles. The dilational viscoelasticity of the surface layer determines its ability to resist external disturbances and to avoid the bubble coarsening and rupture [20,21]. It can be seen that the dilational viscoelasticity of the $\mathrm{SiO}_{2}$ nanoparticles with the HY-2 dispersion is higher than that of the HY-2 solution within the experimental frequency range. This is because the $\mathrm{SiO}_{2}$ nanoparticles can attach to the gas-liquid interface and form stronger viscoelastic layers. 


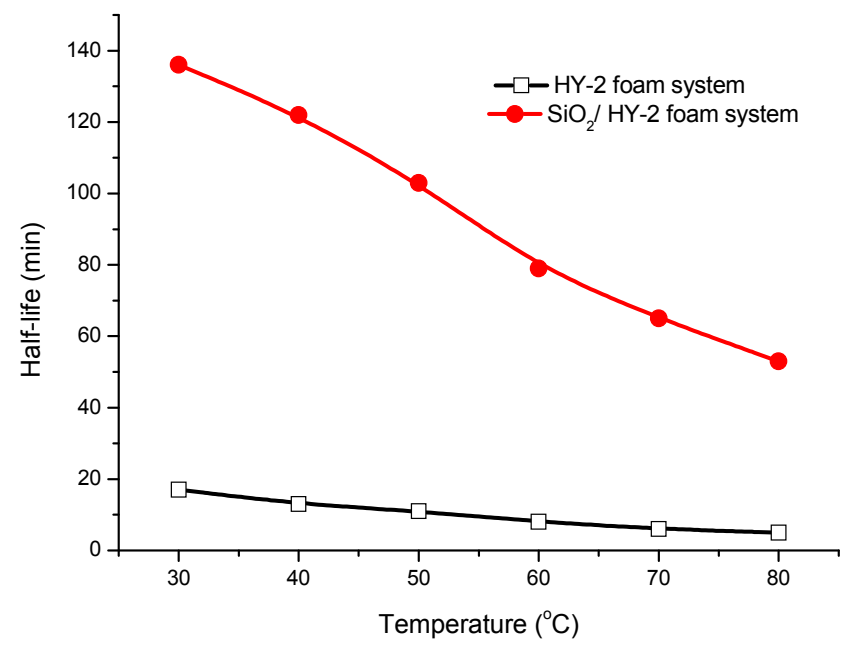

Figure 4. Half-life of various foam systems at different temperatures: $0.5 \mathrm{wt} \% \mathrm{HY}-2$ solution and 1.0 wt $\% \mathrm{SiO}_{2}$ nanoparticles with $0.5 \mathrm{wt} \% \mathrm{HY}-2$ dispersion.

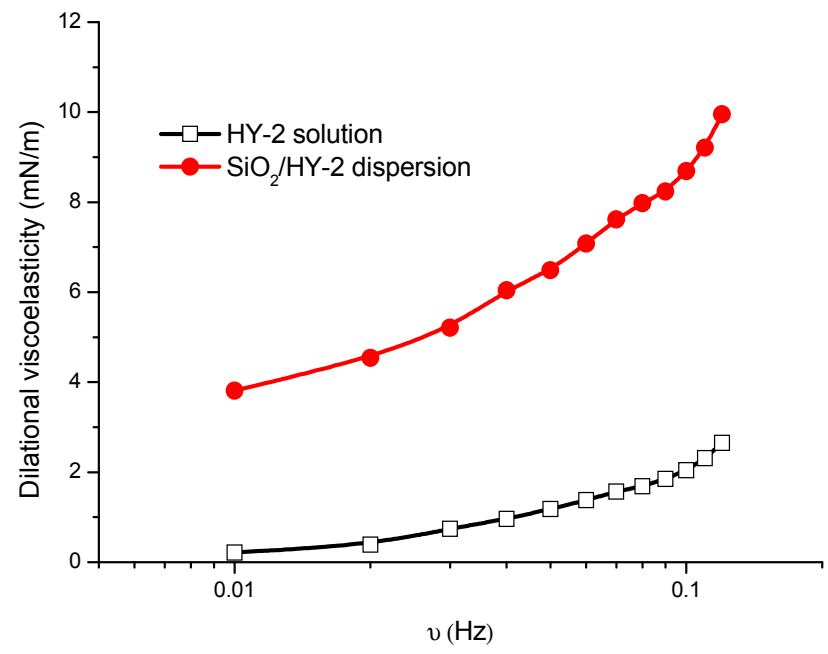

Figure 5. Relationship of dilational viscoelasticity with the frequency of different systems at $30{ }^{\circ} \mathrm{C}$ : $0.5 \mathrm{wt} \% \mathrm{HY}-2$ solution/ $\mathrm{N}_{2}$ interface and $1.0 \mathrm{wt} \% \mathrm{SiO}_{2}$ nanoparticles with $0.5 \mathrm{wt} \% \mathrm{HY}-2$ aqueous dispersion $/ \mathrm{N}_{2}$ interface.

\subsection{Emulsification Tests}

Emulsification tests were conducted to study the emulsification performance of the nanoparticle-surfactant dispersion. Emulsions of oil in two aqueous phases (brine and nanoparticle-surfactant dispersion) are shown in Figure 6. Figure 6a,b show the bottle test for the oil and brine, respectively. It can be seen that the $\mathrm{O} / \mathrm{W}$ emulsion could not be formed in the brine. Figure $6 c, d$ show the emulsification test for the oil and nanoparticle-surfactant dispersion. The results show that oil could be well dispersed in the nanoparticle-surfactant dispersion.

To study the effectiveness of nanoparticles on the $\mathrm{O} / \mathrm{W}$ emulsion stability, the half-life of the emulsion at different temperatures was investigated. As shown in Figure 7, the half-life of the emulsion was higher with a lower temperature. At $30^{\circ} \mathrm{C}$, the half-life of the nanoparticle-surfactant dispersion emulsion was about eight times that of the surfactant emulsion. At $80^{\circ} \mathrm{C}$, the half-life was about 13 times that of the surfactant emulsion. These results indicate that nanoparticles can significantly improve the stability of the $\mathrm{O} / \mathrm{W}$ emulsion. Nanoparticles could form monolayer bridges among the oil droplets (see Figure 8). Nanoparticle bridging plays an important role in the stability of the O/W emulsion and inhibits the individual droplet-droplet coalescence [17]. 

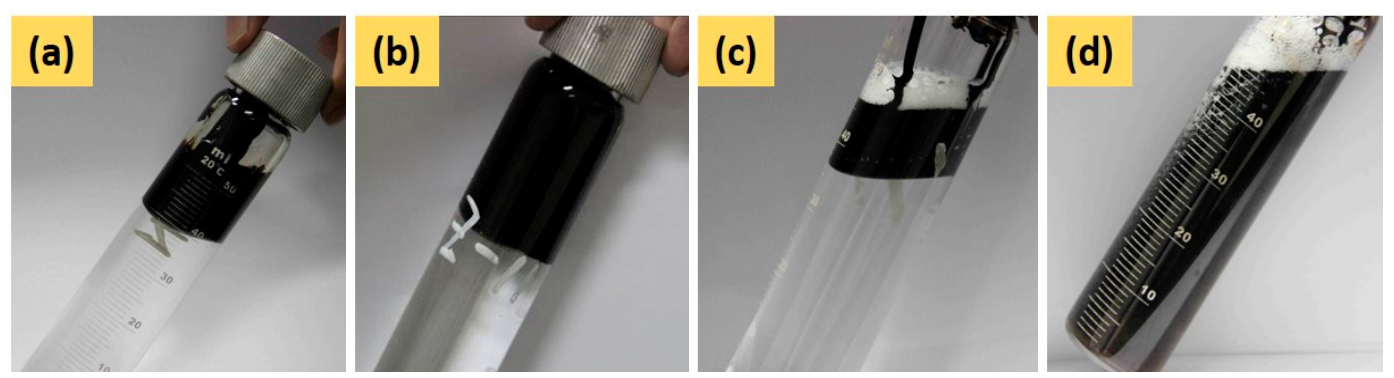

Figure 6. Photos of the bottle test for oil and brine at room temperature. (a) Oil and brine before mixing; (b) Oil and brine after being turned upside down five times; (c) Oil and nanoparticle-surfactant before mixing; (d) Oil and nanoparticle-surfactant after being turned upside down five times.

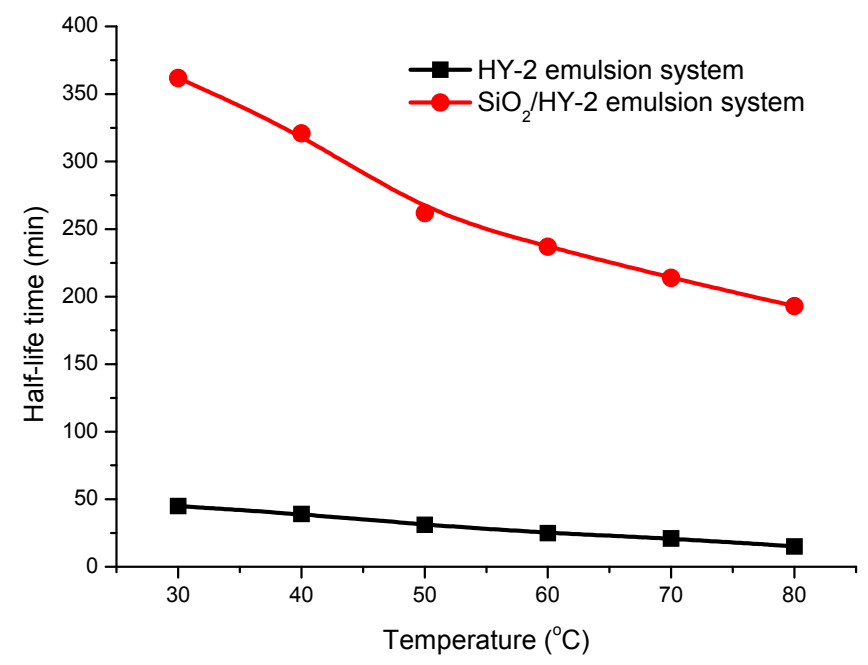

Figure 7. Half-life of the emulsions at different temperatures (surfactant emulsion, 0.5 wt \% HY-2 solution + oil; nanoparticle-surfactant dispersion emulsion, $0.5 \mathrm{wt} \% \mathrm{HY}-2+1 \mathrm{wt} \%$ nanoparticle + oil).

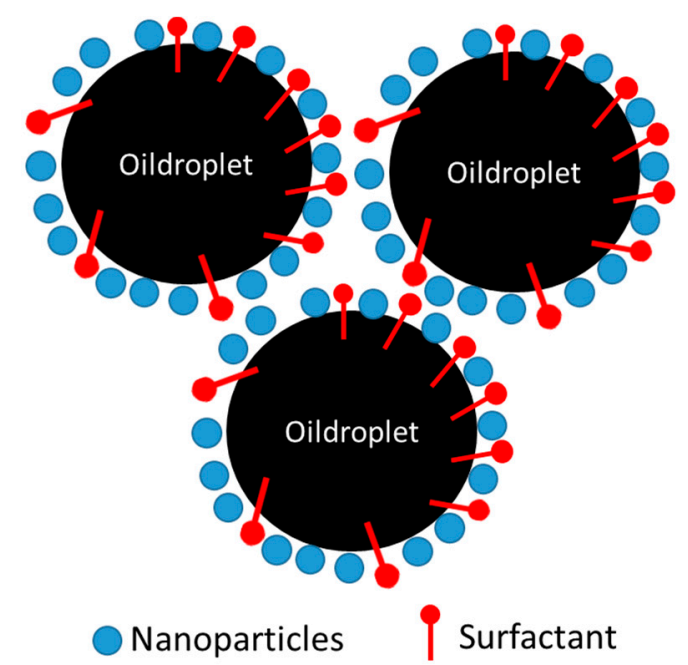

Figure 8. Schematic of nanoparticle bridging between oil droplets.

\subsection{Micromodel Flood Study}

The micromodel test was performed to study the microscopic flow behavior of the nanoparticle-surfactant-stabilized foam for improving heavy oil recovery. 


\subsubsection{Transport of Gas Bubbles in Porous Media}

After the initial water flooding, the nanoparticle-surfactant dispersion and $\mathrm{N}_{2}$ were injected into the micromodel (see Figure 9a). As a result, nanoparticle-surfactant-stabilized gas bubbles are gradually formed near the inlet of the micromodel. The number of gas bubbles increased significantly with the injection of the surfactant solution and $\mathrm{N}_{2}$ (see Figure $9 \mathrm{~b}$ ). Due to the addition of nanoparticles, the gas bubbles were stable and the bubble-bubble coalescence was not observed in the micromodel.
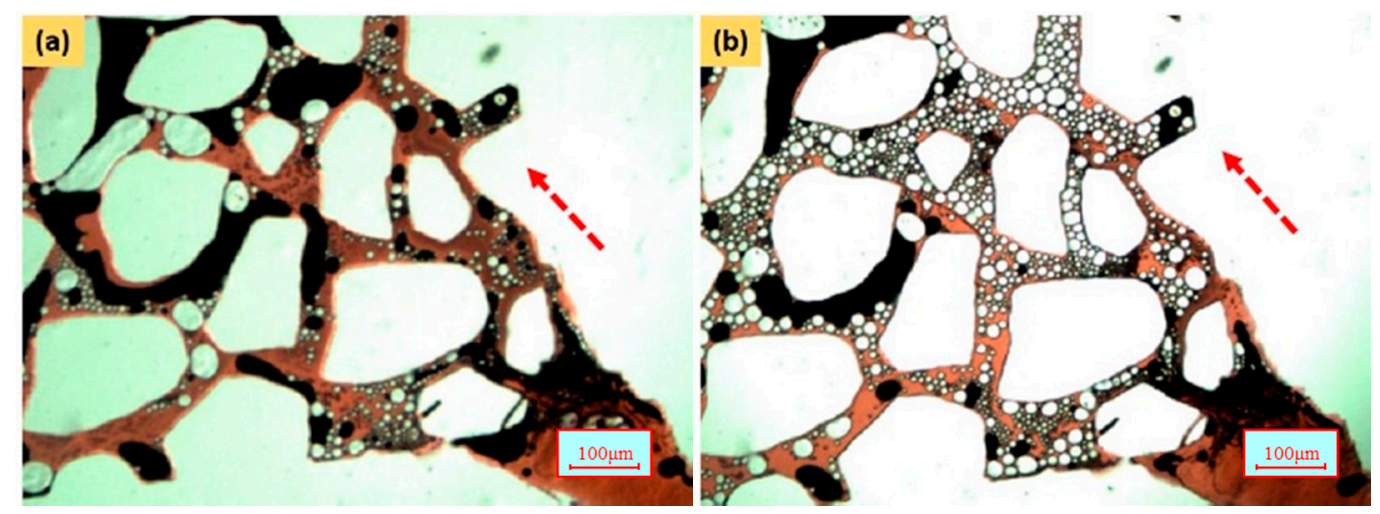

Figure 9. Nanoparticle-surfactant-stabilized gas bubbles near the inlet of the micromodel. (a) 0.01 PV foam injected; (b) 0.2 PV foam injected.

It is clearly observed in Figure 10 that many oil droplets could be stripped and dispersed in porous media because of the emulsification effect of the nanoparticle-surfactant dispersion. In addition, we observed that the flowing gas bubbles can accelerate the formation of emulsified oil droplets (Figure 11). This acceleration can occur because the gas bubbles prefer to remain spherical due to the adsorption of the nanoparticles and surfactant at the water-gas interface [22]. These bubbles will deform when in contact with an oil droplet, as shown in Figure 11a. As shown in Figure 4, the nanoparticles can improve the dilational viscoelasticity of a bubble film. Because of the high viscoelasticity, bubbles tend to recover their spherical shape, which results in the production of a micro-elastic force $\left(F_{\mathrm{e}}\right)$ acting on the oil droplet (see Figure 12). The micro-elastic force is helpful for stripping the oil droplets. Therefore, several oil droplets are formed under the action of gas bubbles (see Figure 11b).

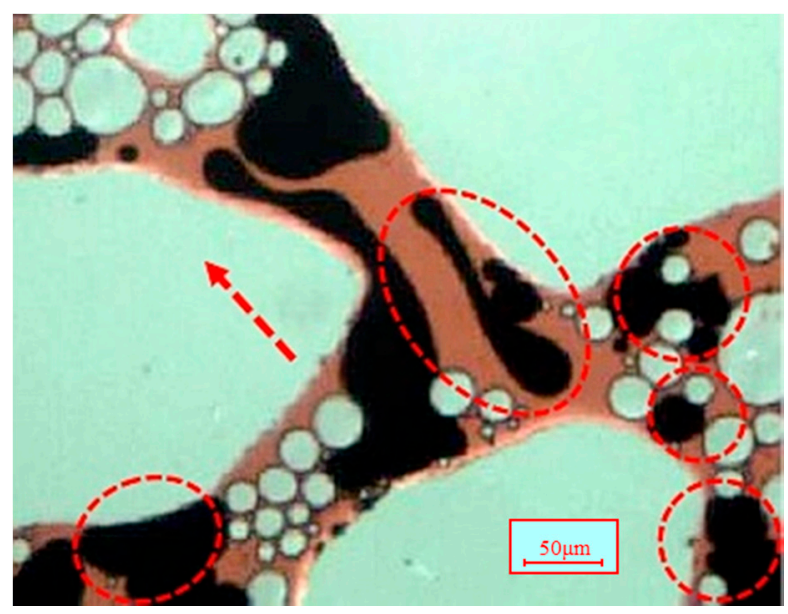

Figure 10. Oil droplets in the porous media. 

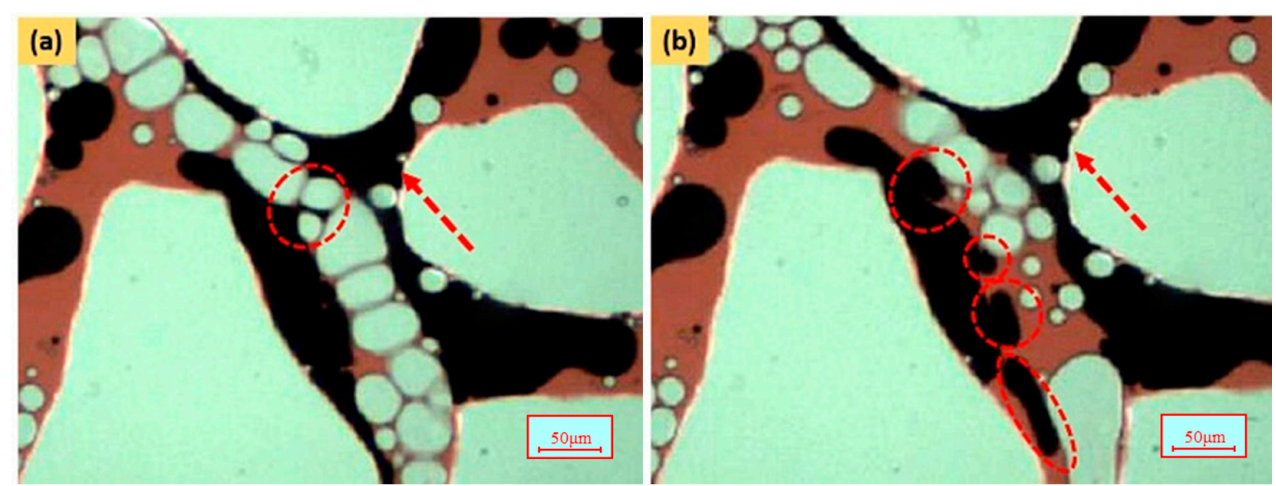

Figure 11. Flowing gas bubbles accelerating the formation of oil droplets. (a) Gas bubbles deform when in contact with an oil droplet; (b) Oil droplets are formed under the action of gas bubbles.

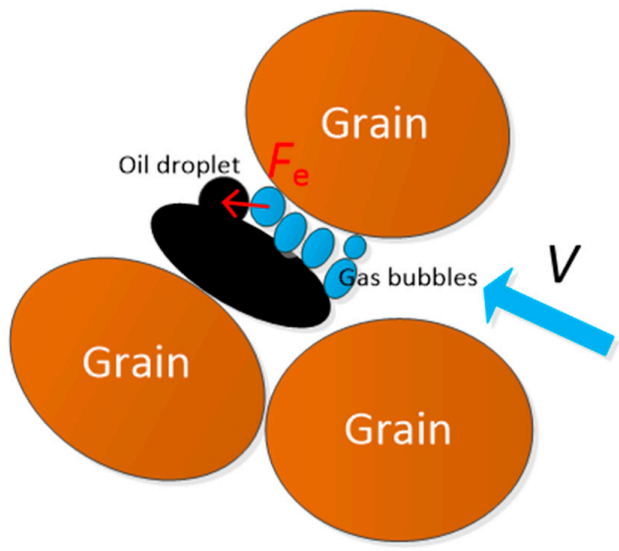

Figure 12. The micro-elastic force $\left(F_{\mathrm{e}}\right)$ of gas bubbles to strip the oil droplet.

Gas bubbles and oil droplets are generated during the injection of the nanoparticle-surfactant dispersion and $\mathrm{N}_{2}$. Because the nanoparticles improve the stability of the foam and $\mathrm{O} / \mathrm{W}$ emulsion, a large number of gas bubbles and oil droplets are stably flowed in the porous media (see Figure 13).

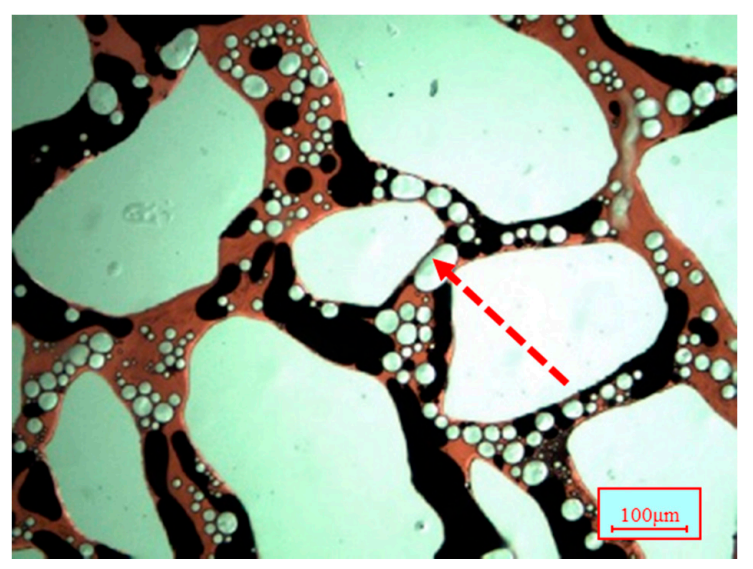

Figure 13. Gas bubbles and oil droplets flowing in the porous media.

Figure 14 shows the gas bubbles driving an oil droplet in the pores. Because of the viscoelasticity of the gas bubbles, the micro-elastic force $\left(F_{\mathrm{e}}\right)$ will act on the oil droplet (see Figure 15). Due to the micro-elastic force, the displacement of oil droplets by gas bubbles can be more effective than by the water. 


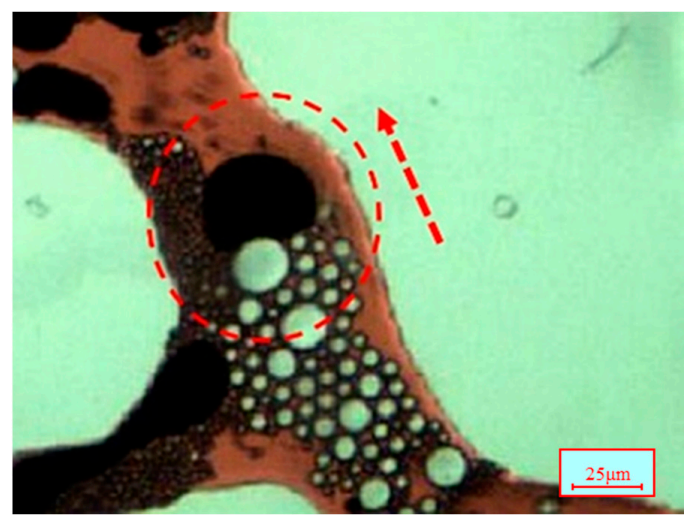

Figure 14. An oil droplet driven by gas bubbles.

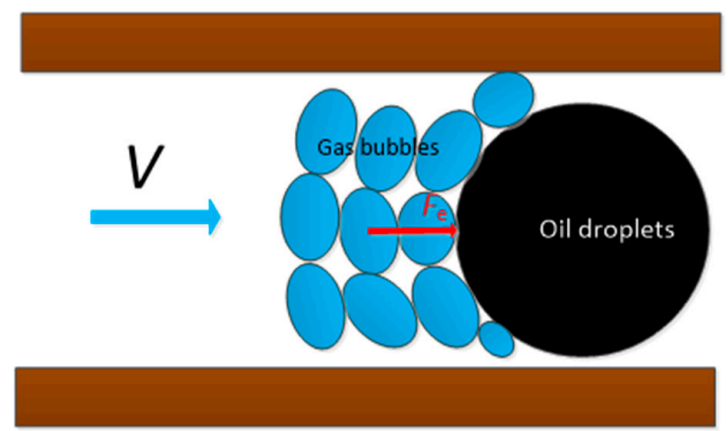

Figure 15. Micro-elastic force $\left(F_{\mathrm{e}}\right)$ acting on the flowing oil droplets.

\subsubsection{Mechanisms for Plugging Pores with Gas Bubbles and Oil Droplets}

The recovery performance of water flooding in heavy oil reservoirs is bad because of the unfavorable mobility ratio between the water and heavy oil. Based on the micromodel test, it was found that the gas bubbles and oil droplets can plug pores in the porous media during the nanoparticle-surfactant-stabilized foam flooding, which can increase the sweep efficiency. There are two main mechanisms for the plugging of pores: capture-plugging and bridge-plugging.

Capture-plugging occurs when a gas bubble or an oil droplet is stuck in a pore-throat with a smaller diameter than the gas bubble or oil droplet particle size (see Figure 16). Based upon the stress analysis, the main forces acting on the gas bubble or oil droplet include the driving force of the fluid $\left(F_{\mathrm{df}}\right)$ and the supportive force of the pore-throat walls $\left(F_{\mathrm{sx}}\right)$ (see Figure 17). The supportive force $F_{\mathrm{s}}$ is related to the deformation of the gas bubble or oil droplet due to the viscoelasticity.
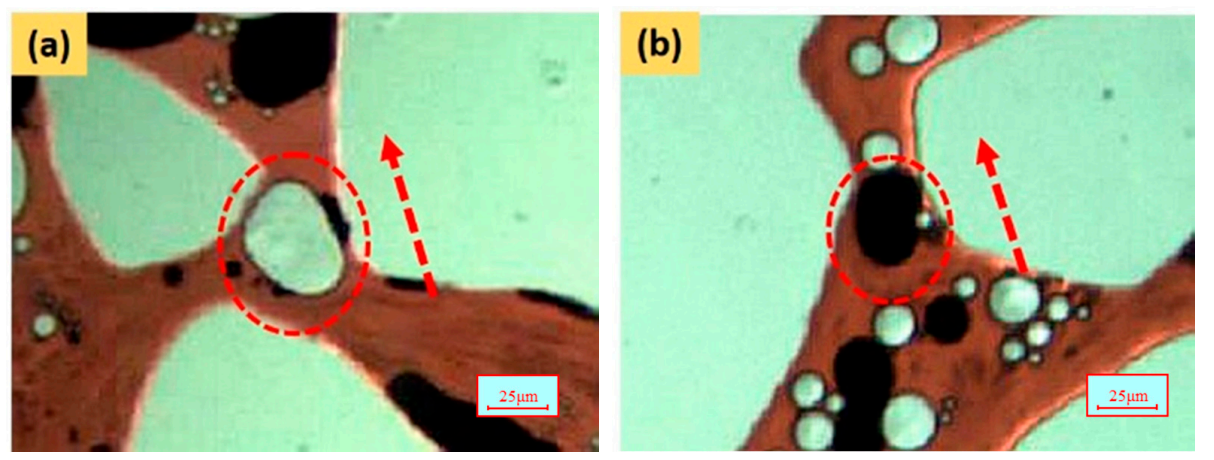

Figure 16. Capture-plugging in pore-throat. (a) Gas bubble capture-plugging; (b) Oil droplet capture-plugging. 


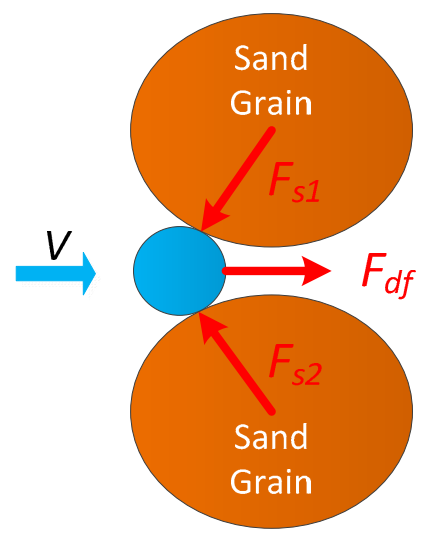

Figure 17. Force analysis for the capture-plugging of pore-throats with gas bubbles.

As shown in Figure 18, it is possible for the gas bubble to pass through the pore-throat after capture. It depends on the viscoelasticity of the gas bubble and the difference of the fluid pressure. In Figure 18a, gas bubbles 1 and 2 are captured by the pore-throats. Gas bubble 1 deforms and gradually enters the pore-throat. This is because the driving force of the fluid $\left(F_{\mathrm{df}}\right)$ on the gas bubble is high enough to overcome the supportive force of the pore-throat walls $\left(F_{\mathrm{s}}\right)$ (see Figure 19a). Then, the gas bubble transforms and flows in the pore-throat (see Figure 18c). After the gas bubble passes through the pore-throat, it will quickly regain its original shape and size (see Figure 18d). The forces acting on the gas bubbles while they remigrate in the pore-throats are shown in Figure 19. However, gas bubble 2 cannot remigrate into the pore-throat because the difference in fluid pressure is not high enough to overcome the supportive force.
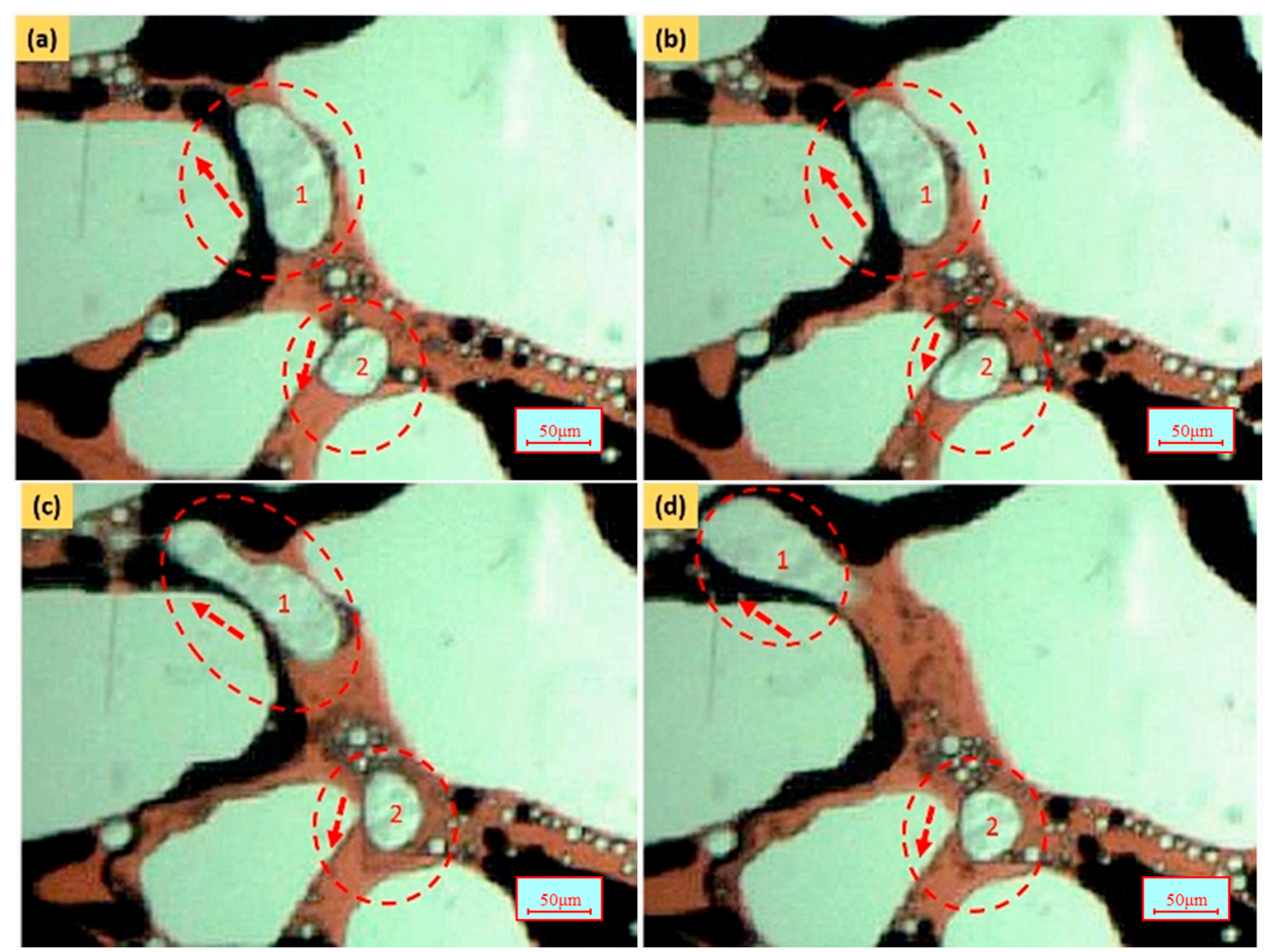

Figure 18. Gas bubble remigration in a pore-throat. (a) $0.251 \mathrm{PV}$ foam injected; (b) 0.262 PV foam injected; (c) 0.271 PV foam injected; (d) 0.275 PV foam injected. 
(a)
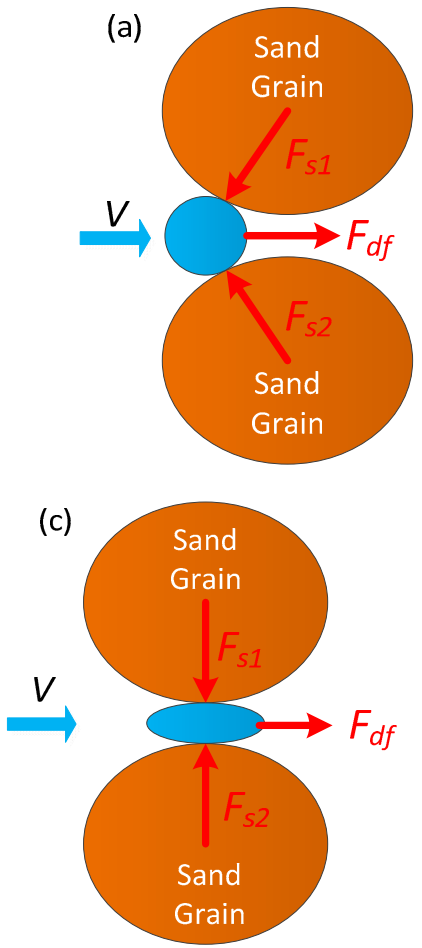

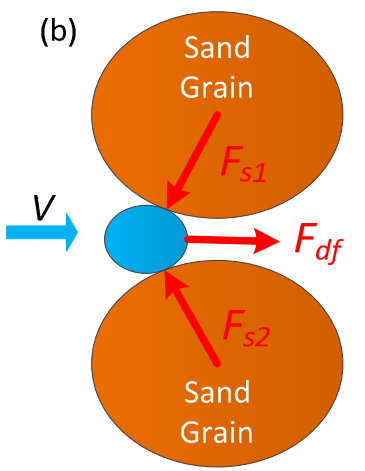

(d)

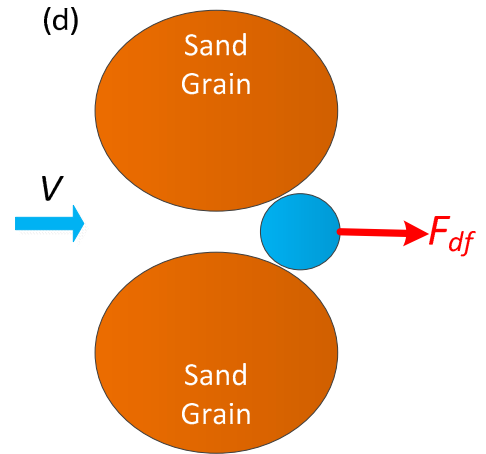

Figure 19. Force analysis during the remigration of gas bubbles in pore-throats. (a) Capture-plugging; (b) Elastic deformation; (c) Steady migration; (d) Deformation recovery.

The results indicate that the viscoelasticity of the gas bubble is very important for capture-plugging. Since the nanoparticles increase the viscoelasticity of the bubble-film (see Figure 4), the supportive force of the nanoparticle-surfactant-stabilized gas bubble is higher than the surfactant stabilized gas bubble under the effect of similar deformation. As a result, the capture-plugging ability of the nanoparticle-surfactant-stabilized gas bubble is better than that of the surfactant stabilized gas bubble.

The second plugging mechanism is bridge-plugging. It is involved with gas bubbles and oil droplets smaller than the pore-throats (see Figure 20). As a gas bubble or oil droplet flows through a pore-throat, the bridging of pore-throats may form. Forming a bridge means that it may get attached to a previously deposited gas bubble and oil droplet. When a bridge is formed and consolidated, the newly arriving gas bubbles accumulate upstream from the bridged pores, thus drastically decreasing the fluid flow rate through these pores. Bridge-plugging is the most important plugging mechanism to enhance plugging strength in actual reservoirs.

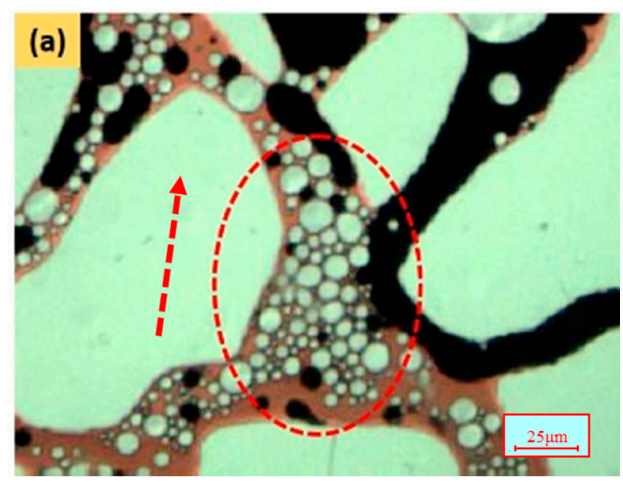

Figure 20. Bridge-plugging in pore-throats. bridge-plugging. (b)

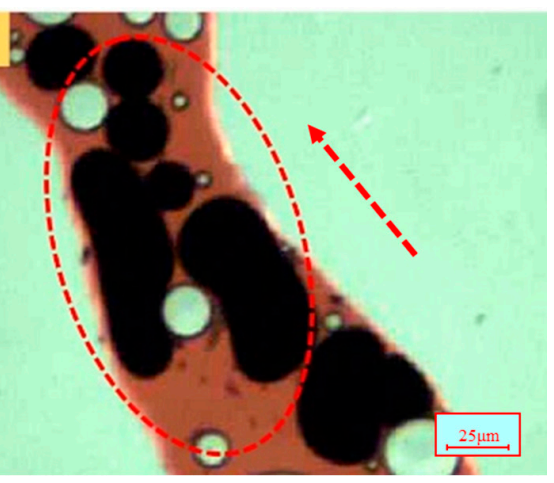
(a) Gas bubble bridge-plugging; (b) Oil droplet 
Pore-bridging consists of several gas bubbles or oil droplets in the pore-throats. Taking as an example the bridge-plugging of two gas bubbles, the main forces acting on the gas bubbles include the driving force of the fluid $\left(F_{\mathrm{df}}\right)$, the supportive force of the pore-throat walls $\left(F_{\mathrm{s}}\right)$, and the extruding force $\left(F_{\mathrm{ex}}\right)$ between the bubbles (see Figure 21$)$. The bridge-plugging is clearly affected by the pore-throat size, gas bubble size, bubble viscoelasticity, the quantity of bubbles in the bridges, and the degree of compaction of the bubbles. The supportive force $\left(F_{\mathrm{s}}\right)$ and the extruding force $\left(F_{\mathrm{ex}}\right)$ are both related to the bubble viscoelasticity. The results show that the ability of bridge-plugging increases with an increase in the bubble viscoelasticity.

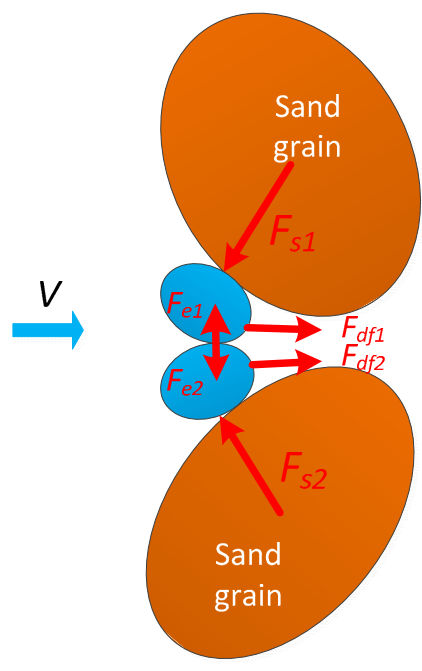

Figure 21. Force analysis for bridge-plugging in pore-throats with gas bubbles.

\subsubsection{Mechanisms for Displacing Residual Oil with Gas Bubbles}

The nanoparticle-surfactant-stabilized foam flooding can improve sweep efficiency by capture-plugging and bridge-plugging. However, some residual oil droplets remain trapped in the pore-throats, as shown in Figure 22. In the following section, the mechanisms of displacing the residual oil by nanoparticle stabilized foam flooding are discussed.

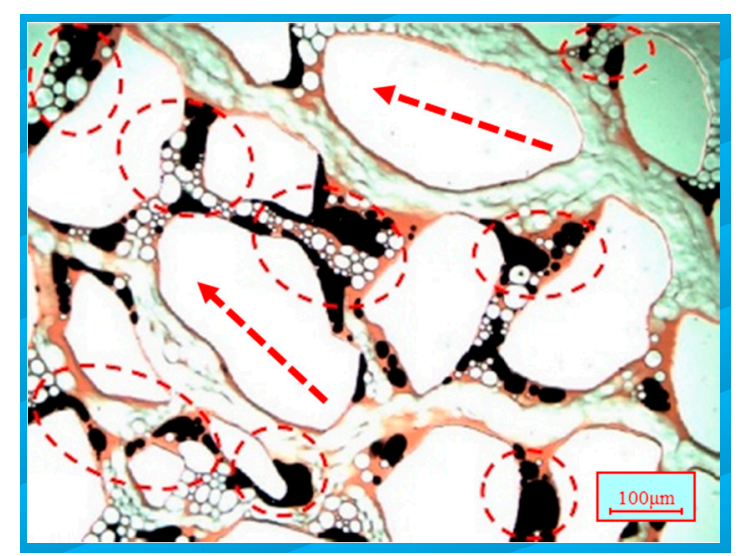

Figure 22. Image of residual oil droplets trapped in the sand grains.

Water is a Newtonian fluid and during the process of water flooding, it can only push the oil along the displacement front, which leaves a large number of residual oil droplets beside the streamline (see Figure 23). For the nanoparticle-surfactant-stabilized foam flooding, the elastic forces of the gas bubbles will act on the residual oil droplets due to the high viscoelasticity of the gas bubbles 
(see Figure 24). Therefore, the trapped oil droplets will gradually be pushed into the pores by gas bubbles, as shown in Figure 25.

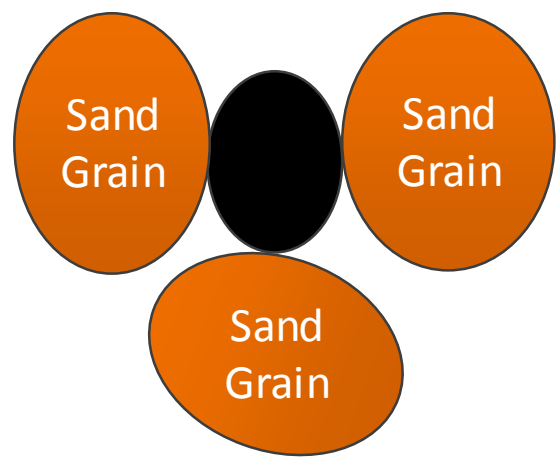

Figure 23. Residual oil droplet trapping after water flooding.

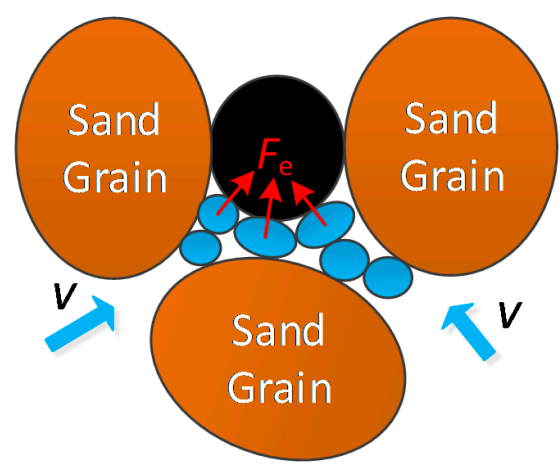

Figure 24. The micro-elastic force $\left(F_{\mathrm{e}}\right)$ acting on residual oil droplets trapped in pore-throats.
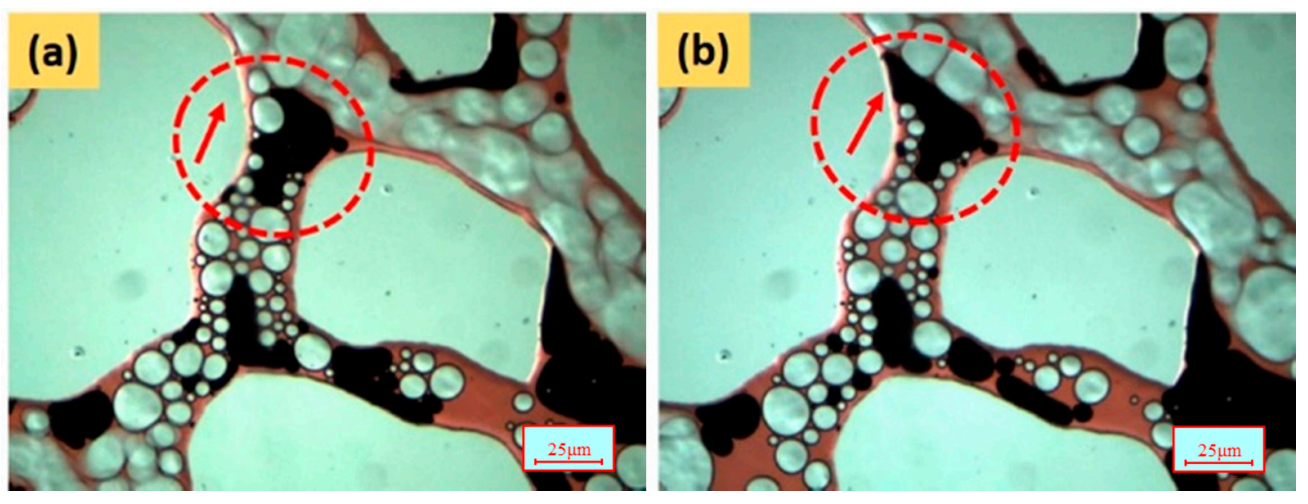

Figure 25. Pore-scale images of the residual oil droplets pushed by the gas bubbles. (a) 0.105 PV; (b) $0.124 \mathrm{PV}$.

As the trapped oil droplets are pushed into the pores, the flowing gas bubbles can pull the oil droplet into oil threads (see Figure 26). It can be observed in Figure 27 that the residual oil droplet at the interchange of the pores can be pulled into an oil thread. This is also due to the viscoelasticity of the bubbles. The deformation of gas bubbles will occur when in contact with the trapped oil droplets. Later on, bubbles can recover their spherical shape, which will produce an elastic force $\left(F_{\mathrm{e}}\right)$ acting on the oil droplet, as shown in Figure 11. The elastic forces can change the shape of the oil droplet and mobilize it (see Figures 28 and 29). As a result, the residual oil droplets could be pulled into oil threads. Therefore, the residual oil can be recovered by nanoparticle-surfactant-stabilized foam flooding, and a greater improvement in the displacement efficiency can be obtained. 

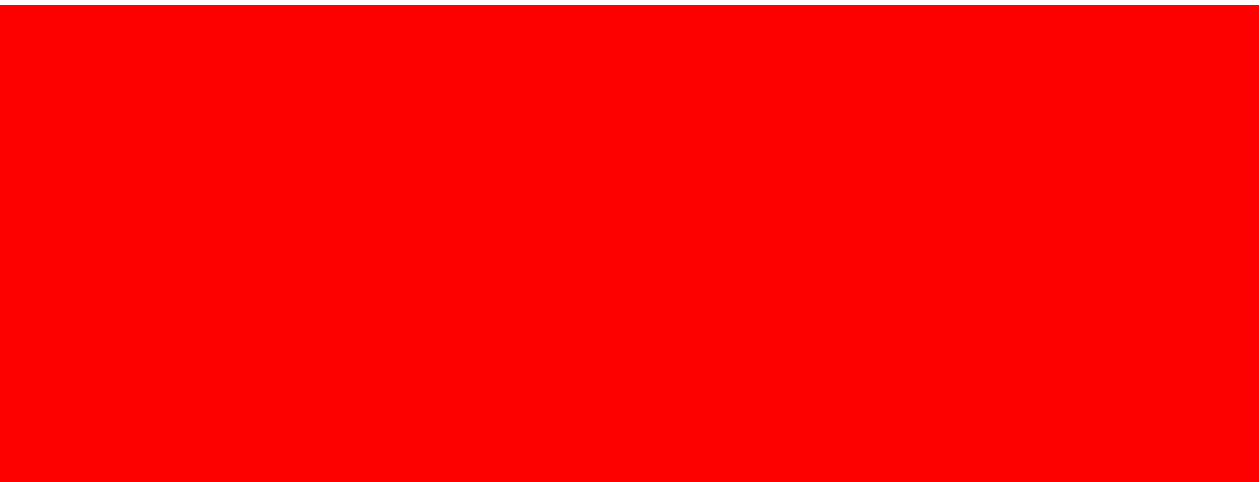

Figure 26. Pore-level images of the formation of oil threads. (a) $0.108 \mathrm{PV}$; (b) $0.135 \mathrm{PV}$.
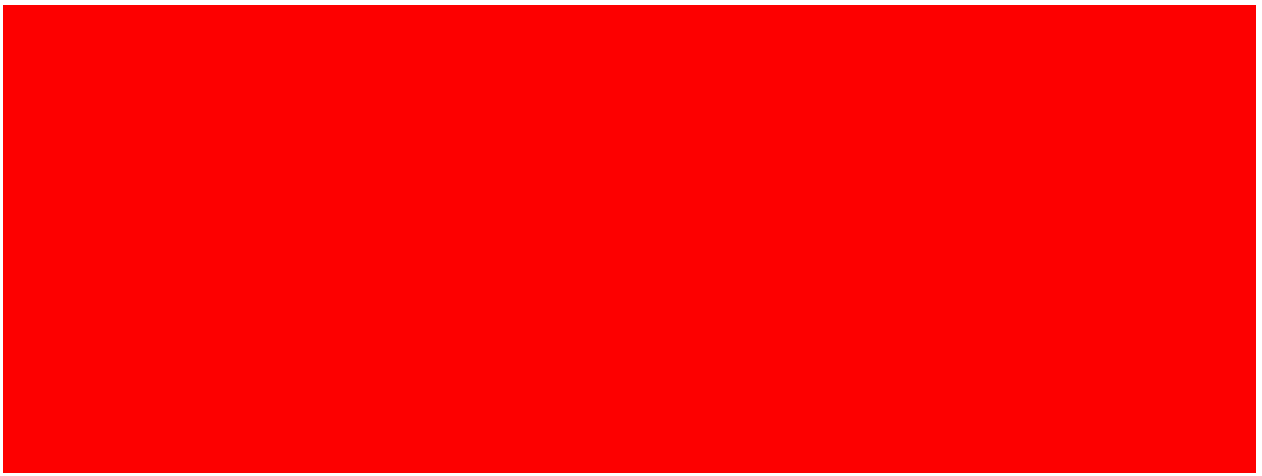

Figure 27. Pore-level images of the formation of oil threads in the interchange of pores. (a) 0.148 PV; (b) $0.159 \mathrm{PV}$.

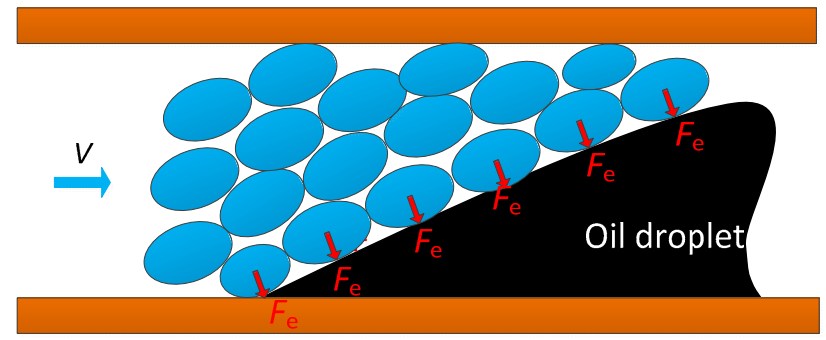

Figure 28. The micro-elastic force $\left(F_{\mathrm{e}}\right)$ of gas bubbles mobilizing oil droplets.

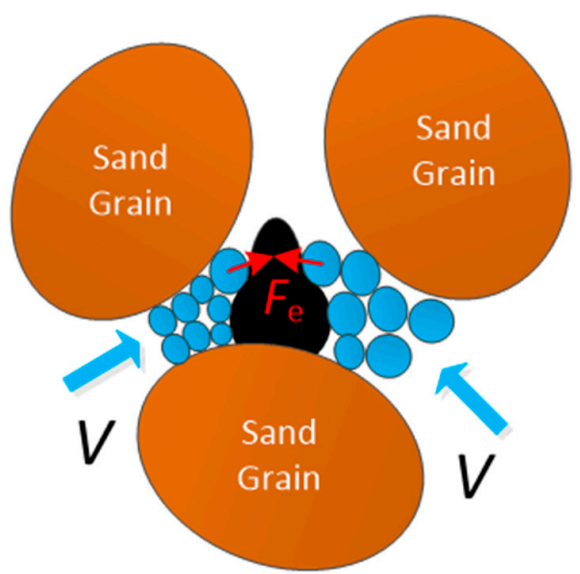

Figure 29. The micro-elastic force $\left(F_{\mathrm{e}}\right)$ of gas bubbles mobilizing oil droplets at the interchange of pores. 
Based on the results obtained from the micromodel test, it can be concluded that the nanoparticle-surfactant-stabilized foam can improve sweep efficiency and displace residual oil effectively, thereby improving the heavy oil recovery. The nanoparticles can increase the viscoelasticity of the bubbles, which seems to be very important for foam stability during foam flooding.

\subsection{Sandpack Flood Study}

To investigate the recovery performance of nanoparticle-stabilized foam flooding, 14 flooding tests were carried out in sandpacks. The effects of the nanoparticle concentration, foam slug size, GLR, and injection pattern were studied. Table 2 lists the experimental conditions and flood results for the sandpack tests.

\subsubsection{Effect of the Nanoparticle Concentration}

To investigate the effect of the nanoparticle concentration on tertiary oil recovery by nanoparticle-surfactant-stabilized foam flooding, several flooding tests (Runs 1-5) were carried out with nanoparticle concentrations ranging from 0 to $1.0 \%$. The concentration of surfactant was kept constant at $0.5 \mathrm{wt} \%$. For these tests, the injection rates of the nanoparticle-surfactant dispersion and $\mathrm{N}_{2}$ were both set to be $0.5 \mathrm{~mL} / \mathrm{min}$. The total foam slug was set to be $0.3 \mathrm{PV}$. Figure 30 shows the oil recovery as a function of the nanoparticle concentration. It can be seen that there was a significant increase in recovery with concentrations between $0.1 \mathrm{wt} \%$ and $0.5 \mathrm{wt} \%$. Afterwards, the increase in oil recovery with the nanoparticle concentration became very slight. It can be concluded that the $0.5 \mathrm{wt} \%$ nanoparticle concentration is the optimum nanoparticle concentration in nanoparticle-stabilized foam flooding.

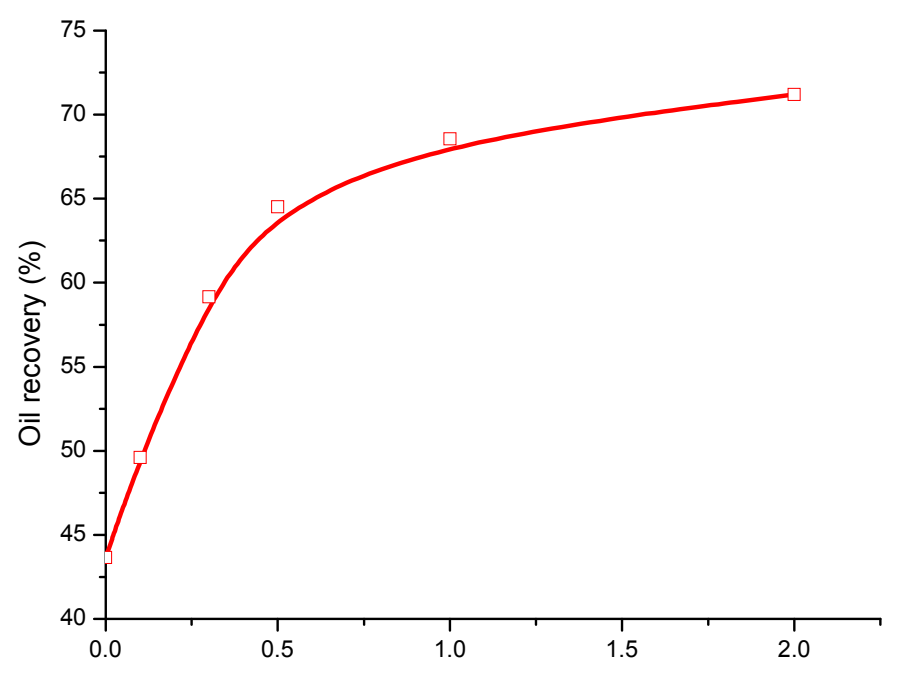

Figure 30. Effect of the nanoparticle concentration on oil recovery.

Figure 31 shows the differential pressure changes as a function of the fluid injected for Runs 1 and 4. It can be seen that the differential pressure of the nanoparticle-stabilized foam flooding $(0.5 \mathrm{wt} \%$ $\left.\mathrm{HY}-2+0.5 \mathrm{wt} \% \mathrm{SiO}_{2}\right)$ was much higher than the HY-2 foam flooding (0.5 wt \% HY-2). The higher built-up differential pressure suggests that the nanoparticle-stabilized foam flooding can block the high-permeability channels and reduce the mobility of the gas phase more effectively. As a result, the subsequent injected water is diverted to the unswept areas, thereby resulting in improved sweep efficiency and increased heavy oil recovery. 
Table 2. Summary of the sandpack tests.

\begin{tabular}{|c|c|c|c|c|c|c|c|c|c|c|c|c|}
\hline \multirow[b]{2}{*}{ Test } & \multicolumn{3}{|c|}{ Properties of Sandpacks } & \multirow{2}{*}{$\begin{array}{l}\text { Waterflood } \\
\text { Recovery } \\
(\%)\end{array}$} & \multirow[b]{2}{*}{ Chemical Formula } & \multirow[b]{2}{*}{$\begin{array}{c}V_{1} \\
(\mathrm{~mL} / \mathrm{min})\end{array}$} & \multirow[b]{2}{*}{$\underset{(\mathrm{mL} / \mathrm{min})}{V_{\mathrm{g}}}$} & \multirow[b]{2}{*}{ GLR } & \multirow[b]{2}{*}{$\begin{array}{c}\text { Foam Slug } \\
\text { Size (PV) }\end{array}$} & \multirow[b]{2}{*}{$\begin{array}{c}\text { Injection } \\
\text { Pattern }\end{array}$} & \multirow{2}{*}{$\begin{array}{c}\text { Tertiary } \\
\text { Recovery } \\
(\%)\end{array}$} & \multirow{2}{*}{$\begin{array}{c}\text { Final } \\
\text { Recovery } \\
(\%)\end{array}$} \\
\hline & $\begin{array}{c}\Phi \\
(\%)\end{array}$ & $\begin{array}{c}K \\
(\mathrm{mD})\end{array}$ & $\begin{array}{l}S_{\text {oi }} \\
(\%)\end{array}$ & & & & & & & & & \\
\hline 1 & 35.21 & 1024 & 0.78 & 38.14 & 0.5 wt \% HY-2 & 0.5 & 0.5 & 1:1 & 0.3 & co-injection & 5.51 & 43.65 \\
\hline 2 & 32.14 & 1089 & 0.75 & 36.24 & $0.5 \mathrm{wt} \% \mathrm{HY}-2+0.1 \mathrm{wt} \% \mathrm{SiO}_{2}$ & 0.5 & 0.5 & $1: 1$ & 0.3 & co-injection & 13.37 & 49.61 \\
\hline 3 & 35.36 & 1152 & 0.71 & 36.95 & $0.5 \mathrm{wt} \% \mathrm{HY}-2+0.3 \mathrm{wt} \% \mathrm{SiO}_{2}$ & 0.5 & 0.5 & $1: 1$ & 0.3 & co-injection & 22.2 & 59.15 \\
\hline 4 & 36.95 & 1247 & 0.76 & 37.15 & $0.5 \mathrm{wt} \% \mathrm{HY}-2+0.5 \mathrm{wt} \% \mathrm{SiO}_{2}$ & 0.5 & 0.5 & $1: 1$ & 0.3 & co-injection & 27.37 & 64.52 \\
\hline 5 & 34.21 & 1026 & 0.81 & 38.06 & $0.5 \mathrm{wt} \% \mathrm{HY}-2+1.0 \mathrm{wt} \% \mathrm{SiO}_{2}$ & 0.5 & 0.5 & $1: 1$ & 0.3 & co-injection & 30.51 & 68.57 \\
\hline 6 & 36.98 & 1125 & 0.79 & 38.36 & $0.5 \mathrm{wt} \% \mathrm{HY}-2+2.0 \mathrm{wt} \% \mathrm{SiO}_{2}$ & 0.5 & 0.5 & $1: 1$ & 0.3 & co-injection & 32.85 & 71.21 \\
\hline 7 & 35.68 & 1201 & 0.81 & 36.95 & $0.5 \mathrm{wt} \% \mathrm{HY}-2+0.5 \mathrm{wt} \% \mathrm{SiO}_{2}$ & 0.5 & 0.5 & $1: 1$ & 0.1 & co-injection & 13.7 & 50.65 \\
\hline 8 & 39.32 & 1036 & 0.71 & 36.32 & $0.5 \mathrm{wt} \% \mathrm{HY}-2+0.5 \mathrm{wt} \% \mathrm{SiO}_{2}$ & 0.5 & 0.5 & $1: 1$ & 0.4 & co-injection & 32.21 & 68.53 \\
\hline 9 & 35.14 & 1158 & 0.74 & 38.14 & $0.5 \mathrm{wt} \% \mathrm{HY}-2+0.5 \mathrm{wt} \% \mathrm{SiO}_{2}$ & 0.5 & 0.5 & $1: 1$ & 0.5 & co-injection & 31.22 & 69.36 \\
\hline 10 & 36.32 & 1135 & 0.72 & 37.15 & $0.5 \mathrm{wt} \% \mathrm{HY}-2+0.5 \mathrm{wt} \% \mathrm{SiO}_{2}$ & 0.34 & 0.66 & $2: 1$ & 0.4 & co-injection & 34.2 & 71.35 \\
\hline 11 & 34.58 & 1058 & 0.73 & 38.06 & $0.5 \mathrm{wt} \% \mathrm{HY}-2+0.5 \mathrm{wt} \% \mathrm{SiO}_{2}$ & 0.25 & 0.75 & $3: 1$ & 0.4 & co-injection & 34.89 & 72.95 \\
\hline 12 & 38.65 & 1063 & 0.76 & 36.96 & $0.5 \mathrm{wt} \% \mathrm{HY}-2+0.5 \mathrm{wt} \% \mathrm{SiO}_{2}$ & 0.2 & 0.8 & $4: 1$ & 0.4 & co-injection & 33.4 & 70.36 \\
\hline 13 & 36.25 & 1114 & 0.75 & 38.35 & $0.5 \mathrm{wt} \% \mathrm{HY}-2+0.5 \mathrm{wt} \% \mathrm{SiO}_{2}$ & 0.25 & 0.75 & $3: 1$ & $0.1+0.3$ & $\begin{array}{c}\text { nanoparticle } \\
\text { dispersion } \\
\text { alternating } \mathrm{N}_{2}\end{array}$ & 26.33 & 64.68 \\
\hline 14 & 39.63 & 1031 & 0.69 & 39.65 & $0.5 \mathrm{wt} \% \mathrm{HY}-2+0.5 \mathrm{wt} \% \mathrm{SiO}_{2}$ & 0.25 & 0.75 & $3: 1$ & $\begin{array}{c}0.05+0.15+ \\
0.05+0.15\end{array}$ & $\begin{array}{c}\text { nanoparticle } \\
\text { dispersion } \\
\text { alternating } \mathrm{N}_{2}\end{array}$ & 28.52 & 68.17 \\
\hline
\end{tabular}




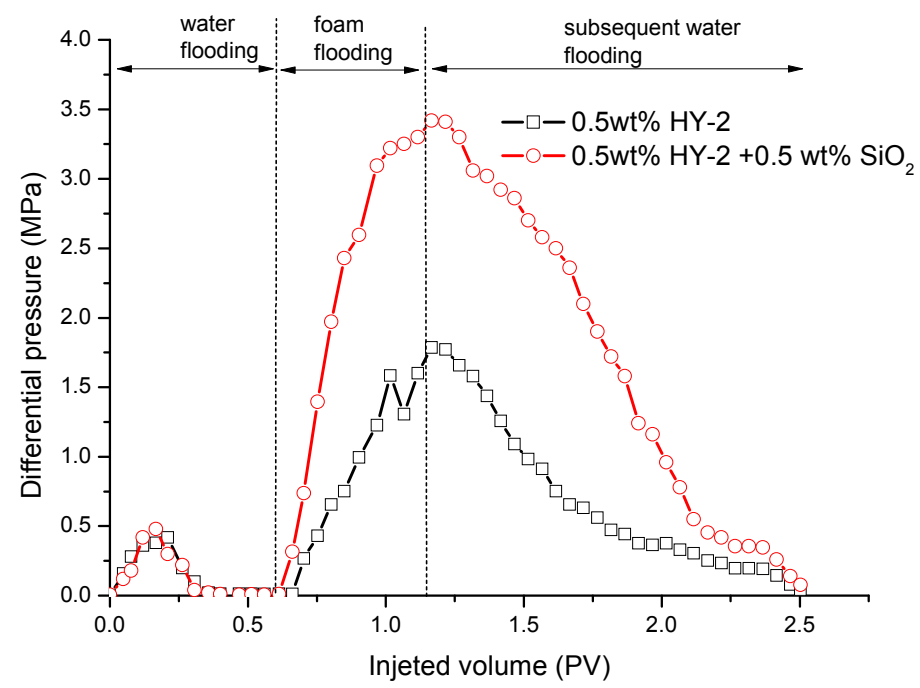

Figure 31. Differential pressure changes as a function of the fluid injected for Runs 1 and 4.

\subsubsection{Effect of the Foam Slug Size}

To investigate the effect of the foam slug size on recovery performance, four sandpack flood tests (Runs 4, 7-9) were conducted by using different foam slug sizes: $0.3,0.1,0.4$, and $0.5 \mathrm{PV}$, respectively. The $\mathrm{SiO}_{2}$ and surfactant concentrations were both set to be $0.5 \mathrm{wt} \%$. Figure 32 shows the oil recovery as a function of the foam slug size. When the foam slug size was less than $0.4 \mathrm{PV}$, the oil recovery increased obviously with the foam slug size. However, as the foam slug size increased higher the $0.4 \mathrm{PV}$, the increment of the oil recovery was not significant. Base on the above results, the optimized foam slug size was $0.4 \mathrm{PV}$.

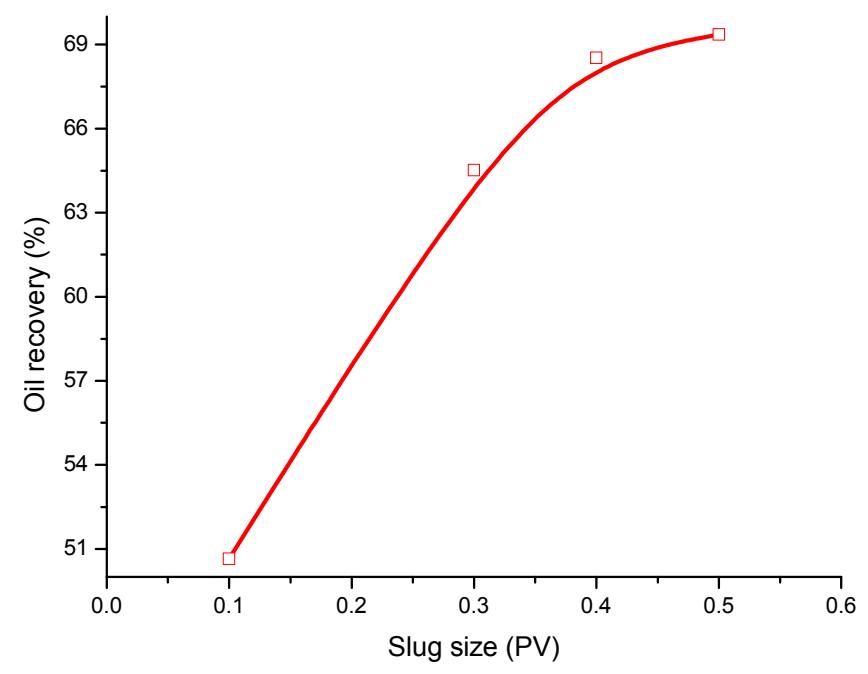

Figure 32. Effect of foam slug size on oil recovery.

\subsubsection{Effect of Gas Liquid Ratio}

The gas liquid ratio is the ratio between the gas flow rate and $\mathrm{N}_{2}$ flow rate under the experimental conditions during the foam flooding. To study the effect of the gas liquid ratio on recovery performance, three flooding tests (Runs 8, 11-12) were carried out. The gas liquid ratios were set to be 1:1, 2:1, 3:1, and 4:1, respectively. The total foam slugs in these tests were 0.4 PV. Figure 33 shows the oil recovery as a function of the gas liquid ratio. As GLR increased, the oil recovery first increased and then later 
decreased. The oil recovery was highest at a GLR of 3:1. Therefore, the optimized GLR was 3 for the nanoparticle stabilized foam flooding, to enhance the heavy oil recovery.

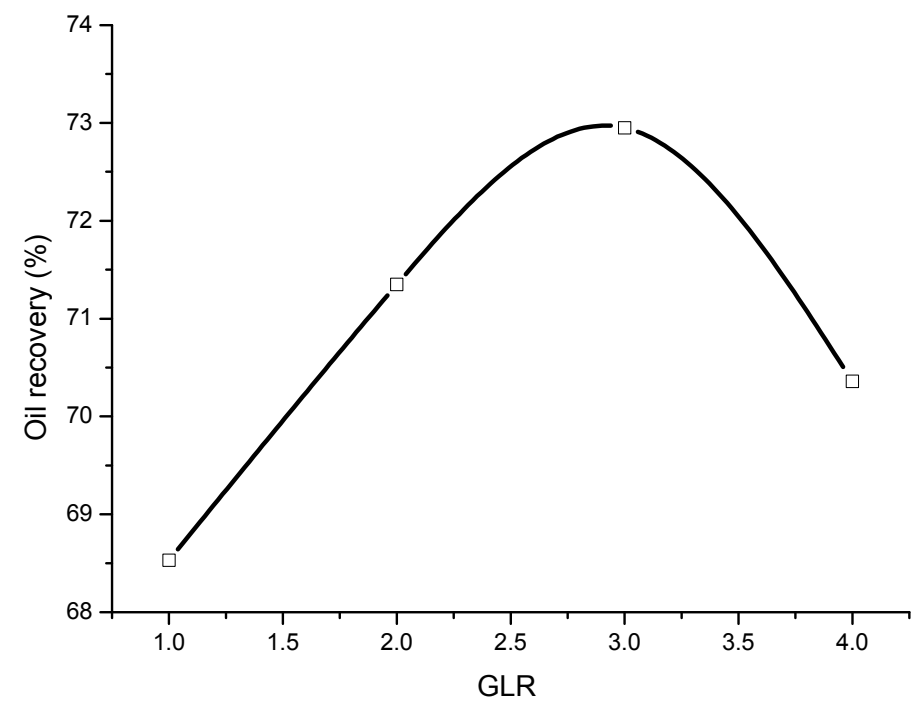

Figure 33. Effect of the GLR on oil recovery.

\subsubsection{Effect of the Injection Pattern}

To study the effect of the injection pattern on the recovery performance of nanoparticle-surfactantstabilized foam flooding, three flooding tests (Runs 11,13-14) were conducted by different injection patterns. The foam slug size and GLR were set to be $0.4 \mathrm{PV}$ and 3:1, respectively. The nanoparticle $\mathrm{SiO}_{2}$ dispersion slug and $\mathrm{N}_{2}$ slug were injected through different patterns, as shown in Figure 34 . For Run 11, the 0.3 PV N $\mathrm{N}_{2}$ slug and 0.1 PV nanoparticle dispersion slug were injected into the sandpack simultaneously. For Runs 13 and 14, the nanoparticle dispersion slug was injected firstly, and then the $\mathrm{N}_{2}$ slug was injected. The nanoparticle dispersion slug size of each injection was $0.1 \mathrm{PV}$ and $0.05 \mathrm{PV}$, respectively. Figure 35 shows the oil recovery for each test. It can be seen that the oil recovery of the test with the co-injection pattern (Run 11) was higher than that of the test with the nanoparticle dispersion alternating $\mathrm{N}_{2}$ injection pattern (Runs 13 and 14). For the nanoparticle dispersion alternating $\mathrm{N}_{2}$ injection pattern, the oil recovery of Run 14 is higher than that of Run 13. This indicates that the recovery performance of the nanoparticle stabilized foam flooding was better with a more frequent cyclic slug. Therefore, the injection pattern is recommended to select the $\mathrm{N}_{2}$ and nanoparticle dispersion co-injection pattern.

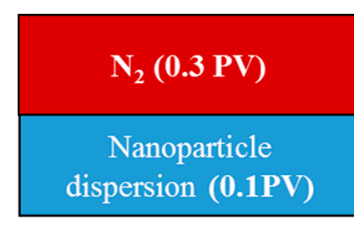

\section{Run 11}

dispersion $(0.1 \mathrm{PV})$

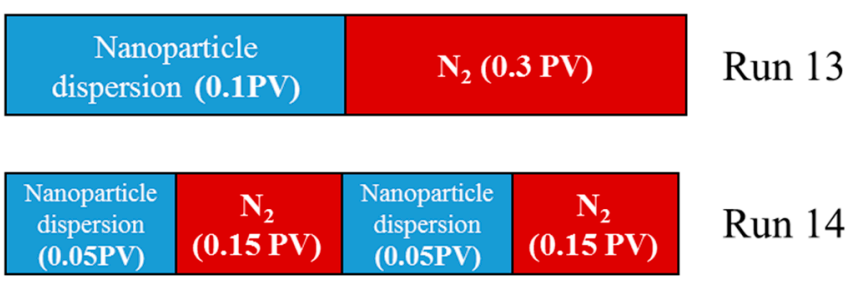

Figure 34. Injection patterns of the nanoparticle dispersion and $\mathrm{N}_{2}$. 


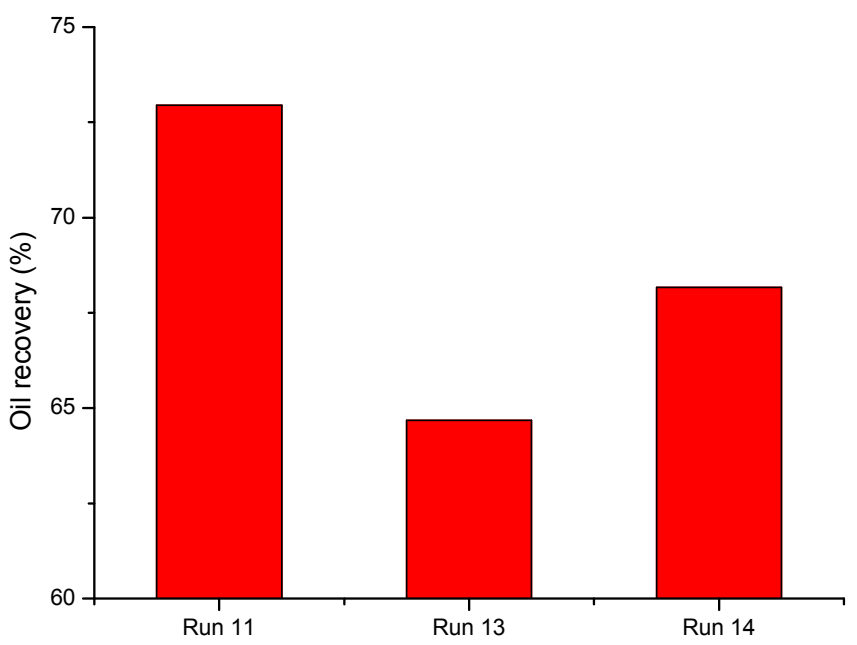

Figure 35. Effect of the injection pattern on oil recovery.

\section{Conclusions}

(1) The stabilities of the foam and $\mathrm{O} / \mathrm{W}$ emulsion increase when silica nanoparticles were added. As a result, a large number of gas bubbles and oil droplets were stably dispersed in the porous media during the nanoparticle stabilized foam flooding.

(2) The $\mathrm{SiO}_{2}$ nanoparticles can increase the dilational viscoelasticity of the gas-water interface, which is an important phenomenon for improving the enhanced heavy oil recovery. The gas bubbles and oil droplets can plug pores through the mechanisms of capture-plugging and bridge-plugging, thereby increasing the sweep efficiency. The trapped residual oil could be pushed to the pores gradually by the elastic forces of gas bubbles, and subsequently, it could be pulled into oil threads by the flowing gas bubbles. As a result, a greater improvement in displacement efficiency is obtained.

(3) The sandpack test results show that the tertiary oil recovery of nanoparticle stabilized foam flooding can reach about $27 \%$ using $0.5 \mathrm{wt} \% \mathrm{SiO}_{2}$ nanoparticles. The foam slug size of $0.3 \mathrm{PV}$ and the gas liquid ratio (GLR) of 3 were found to be the optimum conditions in terms of the heavy oil recovery by nanoparticle stabilized foam flooding in this study. Continuous nanoparticle dispersion and $\mathrm{N}_{2}$ could be more effective when compared with the cyclic injection pattern.

Acknowledgments: This work was supported by the National Natural Science Foundation of China (Grant 51604292) the Natural Science Foundation of Shandong Province, China (Grant ZR2016EEB29) the National Science and Technology Major Project of China (Grant 2017ZX05009004-002) and the Fundamental Research Funds for the Central Universities (Grant 17CX02014A). The authors sincerely thank the colleagues in Foam Fluid Research Center in China University of Petroleum (East China) for helping with the experiments.

Author Contributions: Teng Lu and Zhaomin Li conceived and designed the experiments; Teng Lu and Yan Zhou performed the experiments; Teng Lu and Yan Zhou analyzed the data; Yan Zhou contributed reagents/materials/analysis tools; Teng Lu wrote the paper.

Conflicts of Interest: The authors declare no conflict of interest.

\section{References}

1. Al-Bahlani, A.; Babadagli, T. SAGD laboratory experimental and numerical simulation studies: A review of current status and future issues. J. Pet. Sci. Eng. 2009, 68, 135-150. [CrossRef]

2. Pei, H.; Zhang, G.; Ge, J.; Jin, L.; Ma, C. Potential of alkaline flooding to enhance heavy oil recovery through water-in-oil emulsification. Fuel 2013, 104, 284-293. [CrossRef]

3. Mai, A.; Bryan, J.; Goodarzi, N.; Kantzas, A.; Mai, A.; Bryan, J.; Goodarzi, N.; Kantzas, A. Insights Into Non-Thermal Recovery of Heavy Oil. J. Can. Pet. Technol. 2009, 48, 27-35. [CrossRef] 
4. Kumar, M.; Hoang, V.T.; Satik, C.; Rojas, D.H. High-Mobility-Ratio Waterflood Performance Prediction: Challenges and New Insights. SPE Reserv. Eval. Eng. 2008, 11, 186-196. [CrossRef]

5. Mai, A.; Kantzas, A. Heavy Oil Waterflooding: Effects of Flow Rate and Oil Viscosity. J. Can. Pet. Technol. 2007, 48, 42-51. [CrossRef]

6. Liu, Q.; Dong, M.; Ma, S.; Tu, Y. Surfactant enhanced alkaline flooding for Western Canadian heavy oil recovery. Colloids Surf. A Physicochem. Eng. Asp. 2007, 293, 63-71. [CrossRef]

7. Dong, M.; Ma, S.; Liu, Q. Enhanced heavy oil recovery through interfacial instability: A study of chemical flooding for Brintnell heavy oil. Fuel 2009, 88, 1049-1056. [CrossRef]

8. Zhang, H.; Dong, M.; Zhao, S. Which One Is More Important in Chemical Flooding for Enhanced Court Heavy Oil Recovery, Lowering Interfacial Tension or Reducing Water Mobility? Energy Fuels 2010, 24, 1829-1836. [CrossRef]

9. Benucci, M.; Corvaro, F.; Dall'Acqua, D.; del Monaco, A.; Giacchetta, G.; Marchetti, B. A study to increase the success rate in pipeline deliquification by foamier injection. In Proceedings of the XX Summer School Francesco Turco, Naples, Italy, 6-8 July 2015; pp. 217-223.

10. Pei, H.; Zhang, G.; Ge, J.; Wang, J.; Ding, B.; Liu, X. Investigation of Polymer-Enhanced Foam Flooding with Low Gas/Liquid Ratio for Improving Heavy Oil Recovery. In Proceedings of the Canadian Unconventional Resources and International Petroleum Conference, Calgary, AB, Canada, 19-21 October 2010.

11. Kang, W.; Liu, S.; Meng, L.W.; Cao, D.; Fan, H. A Novel Ultra-Low Interfacial Tension Foam Flooding Agent to Enhance Heavy Oil Recovery. In Proceedings of the SPE Improved Oil Recovery Symposium, Tulsa, OK, USA, 24-28 April 2010.

12. Farzaneh, S.A.; Sohrabi, M. A Review of the Status of Foam Application in Enhanced Oil Recovery. In Proceedings of the EAGE Annual Conference \& Exhibition incorporating SPE Europec, London, UK, 10-13 June 2013.

13. Hassen, J.E.; Dalland, M. Increased Oil Tolerance of Polymer-Enhanced Foams: Deep Chemistry or Just "Simple" Displacement Effects?Recovery Symposium, Tulsa, OK, USA, 3-5 April 2000. In Proceedings of the SPE/DOE Improved Oil Recovery Symposium, Tulsa, OK, USA, 3-5 April 2000.

14. Espinosa, D.; Johnston, K.; Bryant, S.L.; Huh, C. Nanoparticle-Stability Supercritical $\mathrm{CO}_{2}$ Foams for Potential Mobility Control Applications. In Proceedings of the 2010 SPE Improved Oil Recovery Symposium, Society of Petroleum Engineers, Tulsa, OK, USA, 24-28 April 2010.

15. Sun, Q.; Li, Z.; Li, S.; Jiang, L.; Wang, J.; Wang, P. Utilization of surfactant-stabilized foam for enhanced oil recovery by adding nanoparticles. Energy Fuels 2014, 28, 2384-2394. [CrossRef]

16. Nguyen, P.; Fadaei, H.; Sinton, D. Pore-scale assessment of nanoparticle-stabilized $\mathrm{CO}_{2}$ foam for enhanced oil recovery. Energy Fuels 2014, 28, 6221-6227. [CrossRef]

17. Singh, R.; Mohanty, K.K. In Foams Stabilized by In-Situ Surface Activated Nanoparticles in Bulk and Porous Media. In Proceedings of the SPE Technical Conference and Exhibition, Amsterdam, The Netherlands, 27-29 October 2014.

18. Aminzadeh, B.; DiCarlo, D.A.; Chung, D.H.; Kianinejad, A.; Bryant, S.L.; Huh, C. Effect of Nanoparticles on Flow Alteration during $\mathrm{CO}_{2}$ Injection; SPE Paper 1600052; Society of Petroleum Engineers (SPE): Richardson, TX, USA, 2012;

19. Lv, Q.; Li, Z.; Li, B.; Li, S.; Sun, Q. Study of nanoparticle-surfactant-stabilized foam as a fracturing fluid. Ind. Eng. Chem. Res. 2015, 54, 9456-9477. [CrossRef]

20. Santini, E.; Ravera, F.; Ferrari, M.; Alfè, M.; Ciajolo, A.; Liggieri, L. Interfacial properties of carbon particulate-laden liquid interfaces and stability of related foams and emulsions. Colloids Surf. A Physicochem. Eng. Asp. 2010, 365, 189-198. [CrossRef]

21. Hunter, T.N.; Wanless, E.J.; Jameson, G.J.; Pugh, R.J. Non-ionic surfactant interactions with hydrophobic nanoparticles: Impact on foam stability. Colloids Surf. A Physicochem. Eng. Asp. 2009, 347, 81-89. [CrossRef]

22. Walker, E.M.; Frost, D.S.; Dai, L.L. Particle self-assembly in oil-in-ionic liquid Pickering emulsions. J. Colloid Interface Sci. 2011, 363, 307-313. [CrossRef] [PubMed]

(C) 2017 by the authors. Licensee MDPI, Basel, Switzerland. This article is an open access article distributed under the terms and conditions of the Creative Commons Attribution (CC BY) license (http:/ / creativecommons.org/licenses/by/4.0/). 